NASA/TM-2016-219328 (Corrected Copy)

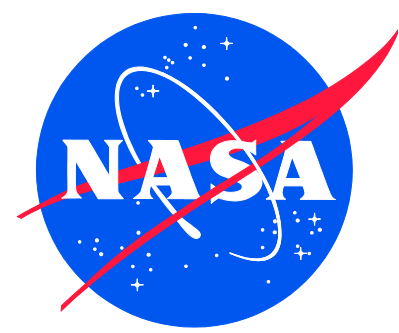

\title{
Permeability of Two Parachute Fabrics - Measurements, Modeling, and Application
}

Juan R. Cruz

NASA Langley Research Center, Hampton, Virginia

Clara O'Farrell

Jet Propulsion Laboratory, Pasadena, California

Elsa Hennings and Paul Runnells

Naval Air Warfare Center Weapons Division, China Lake, California 


\section{NASA STI Program ... in Profile}

Since its founding, NASA has been dedicated to the advancement of aeronautics and space science. The NASA scientific and technical information (STI) program plays a key part in helping NASA maintain this important role.

The NASA STI program operates under the auspices of the Agency Chief Information Officer. It collects, organizes, provides for archiving, and disseminates NASA's STI. The NASA STI program provides access to the NTRS Registered and its public interface, the NASA Technical Reports Server, thus providing one of the largest collections of aeronautical and space science STI in the world. Results are published in both non-NASA channels and by NASA in the NASA STI Report Series, which includes the following report types:

- TECHNICAL PUBLICATION. Reports of completed research or a major significant phase of research that present the results of NASA Programs and include extensive data or theoretical analysis. Includes compilations of significant scientific and technical data and information deemed to be of continuing reference value. NASA counter-part of peerreviewed formal professional papers but has less stringent limitations on manuscript length and extent of graphic presentations.

- TECHNICAL MEMORANDUM. Scientific and technical findings that are preliminary or of specialized interest, e.g., quick release reports, working papers, and bibliographies that contain minimal annotation. Does not contain extensive analysis.

- CONTRACTOR REPORT. Scientific and technical findings by NASA-sponsored contractors and grantees.
- CONFERENCE PUBLICATION. Collected papers from scientific and technical conferences, symposia, seminars, or other meetings sponsored or co-sponsored by NASA.

- SPECIAL PUBLICATION. Scientific, technical, or historical information from NASA programs, projects, and missions, often concerned with subjects having substantial public interest.

- TECHNICAL TRANSLATION. English-language translations of foreign scientific and technical material pertinent to NASA's mission.

Specialized services also include organizing and publishing research results, distributing specialized research announcements and feeds, providing information desk and personal search support, and enabling data exchange services.

For more information about the NASA STI program, see the following:

- Access the NASA STI program home page at http://www.sti.nasa.gov

- E-mail your question to help@sti.nasa.gov

- Phone the NASA STI Information Desk at 757-864-9658

- Write to:

NASA STI Information Desk

Mail Stop 148

NASA Langley Research Center

Hampton, VA 23681-2199 
NASA/TM-2016-219328 (Corrected Copy)

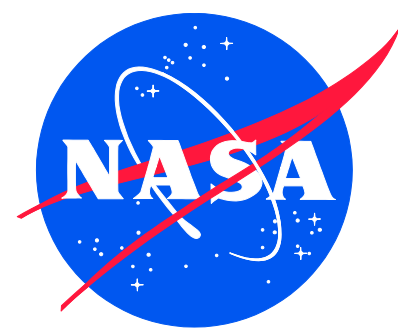

\section{Permeability of Two Parachute Fabrics - Measurements, Modeling, and Application}

Juan R. Cruz

NASA Langley Research Center, Hampton, Virginia

Clara O'Farrell

Jet Propulsion Laboratory, Pasadena, California

Elsa Hennings and Paul Runnells

Naval Air Warfare Center Weapons Division, China Lake, California 


\section{Table of Contents}

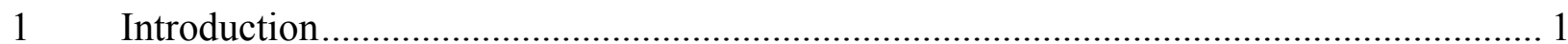

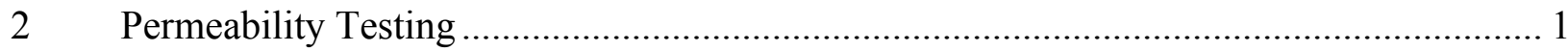

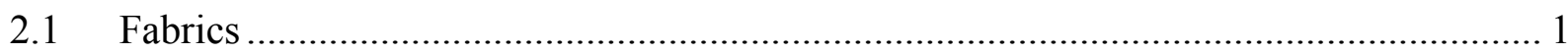

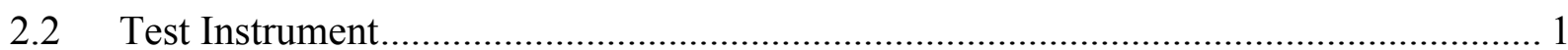

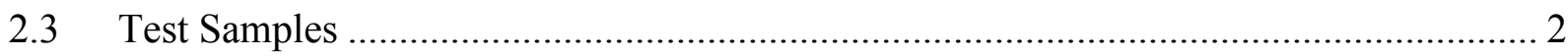

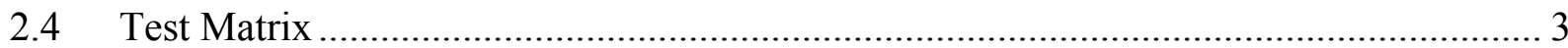

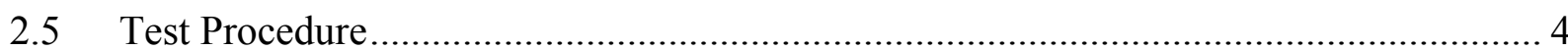

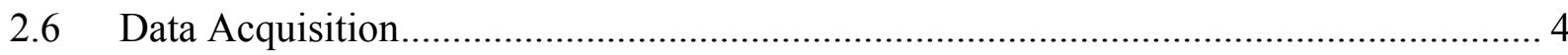

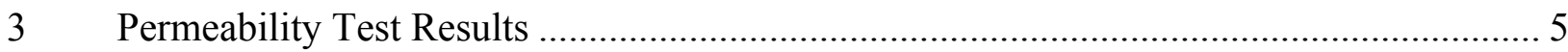

4 Effective Porosity Test Results, Modeling, and Application.............................................. 9

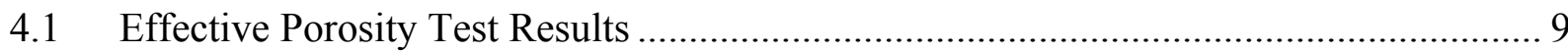

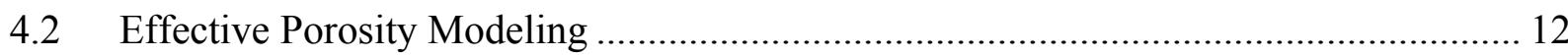

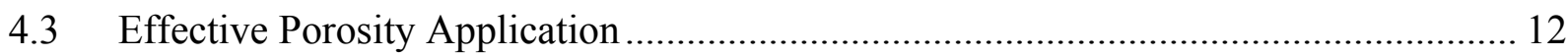

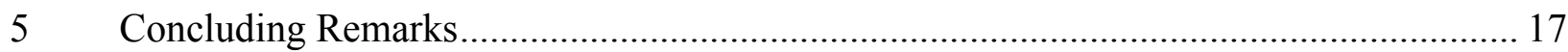

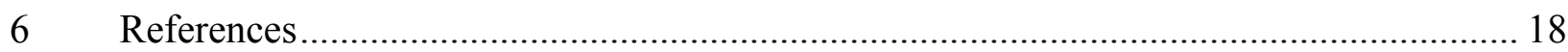

Appendix A Permeability Test Results.......................................................................... 19

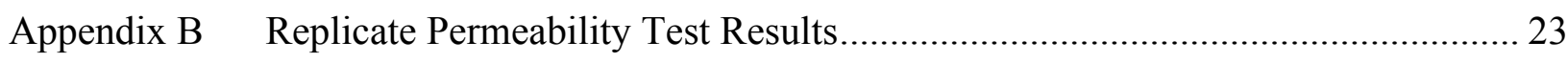

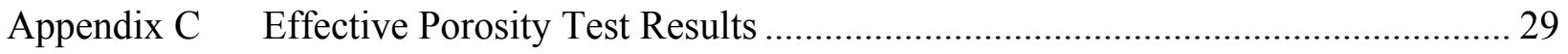




\section{List of Figures}

Figure 1. Test instrument. Portion of fabric being tested is inside circular clamp.................. 2

Figure 2. Position of samples on fabrics............................................................................ 3

Figure 3. Permeability results for PIA-C-7020D Type I fabric ...................................... 6

Figure 4. Permeability results for PIA-C-44378D Type I fabric............................................ 7

Figure 5. Effective porosity results and models for PIA-C-7020D Type I fabric. ................. 10

Figure 6. Effective porosity results and models for PIA-C-44378D Type I fabric................. 11

Figure B1. Original and replicate permeability results for PIA-C-7020D Type I fabric........... 24

Figure B2. Original and replicate permeability results for PIA-C-44378D Type I fabric. ........ 25

\section{List of Tables}

Table 1. Key specification properties of the test fabrics. ........................................... 1

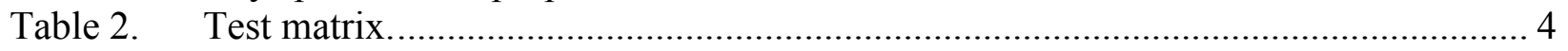

Table 3. Summary of permeability results for PIA-C-7020D Type I fabric. ......................... 8

Table 4. Summary of permeability results for PIA-C-44378D Type I fabric. ...................... 8

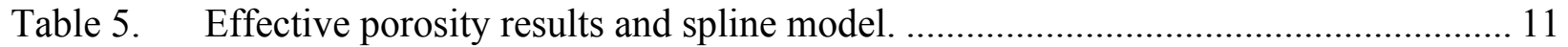

Table 6. Fitted values of $K_{1}$ and $K_{2}$ for both fabrics............................................... 12

Table 7. Example total porosity calculations for two Disk-Gap-Band parachutes. ............... 14

Table 8. Values of constants in equations (11) and (12) for the example.......................... 15

Table 9. Conditions experienced by MSL during descent on Mars at a Mach number of 0.41 , as obtained from flight reconstruction. ................................................... 16

Table 10. Additional data on the MSL parachute............................................................. 16

Table 11. Drag coefficient interpolation results for the MSL on-Mars flight condition

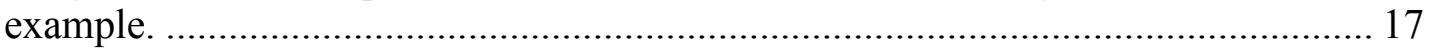

Table A1. Permeability results for PIA-C-7020D Type I fabric in chronological testing

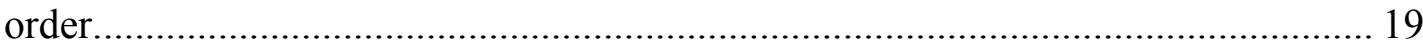

Table A2. Permeability results for PIA-C-44378D Type I fabric in chronological testing

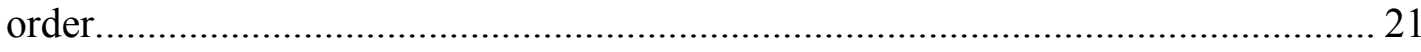

Table B1. Replicate permeability results for PIA-C-7020D Type I fabric in chronological

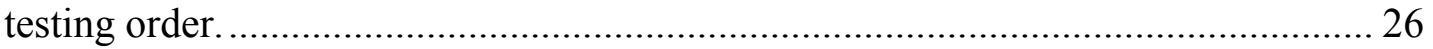

Table B2. Replicate permeability results for PIA-C-44378D Type I fabric in chronological

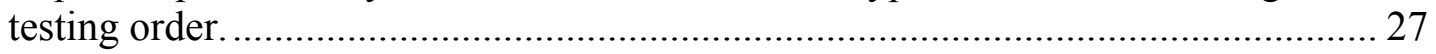

Table C1. Effective porosity results for PIA-C-7020D Type I fabric.................................... 29

Table C2. Effective porosity results for PIA-C-44378D Type I fabric................................. 30 


\section{Summary}

Two parachute fabrics, described by Parachute Industry Specifications PIA-C-7020D Type I and PIA-C-44378D Type I, were tested to obtain their permeabilities in air (i.e., flow-through volume of air per area per time) over the range of differential pressures from $0.146 \mathrm{psf}$ ( $7 \mathrm{~Pa}$ ) to $25 \mathrm{psf}(1197 \mathrm{~Pa})$. Both fabrics met their specification permeabilities at the standard differential pressure of 0.5 inch of water $(2.60 \mathrm{psf}, 124 \mathrm{~Pa})$. The permeability results were transformed into an effective porosity for use in calculations related to parachutes. Models were created that related the effective porosity to the unit Reynolds number for each of the fabrics. As an application example, these models were used to calculate the total porosities for two geometrically-equivalent subscale Disk-Gap-Band (DGB) parachutes fabricated from each of the two fabrics, and tested at the same operating conditions in a wind tunnel. Using the calculated total porosities and the results of the wind tunnel tests, the drag coefficient of a geometrically-equivalent full-scale DGB operating on Mars was estimated. 


\section{Symbols and Abbreviations}

$C_{D} \quad$ parachute drag coefficient (using $S_{0}$ as the reference area)

$C_{0}, C_{1} \quad$ constants in the linear relationships between $\lambda_{T}$ and $C_{D}$; the additional subscripts $M 1$ and $M 2$ are added to these symbols to denote which method was used to determine $\lambda_{T}$

$c_{e} \quad$ effective porosity

$c_{e, \text { Avg }} \quad$ average effective porosity

$K_{1}, K_{2} \quad$ constants in the models for $c_{e}$

$k \quad$ discharge coefficient

$p \quad$ atmospheric (upstream) pressure (in the laboratory)

$q \quad$ dynamic pressure

$R \quad$ gas constant

$\hat{R} e \quad$ unit Reynolds number

$\hat{R} e_{\text {Avg }} \quad$ average unit Reynolds number

$R H \quad$ relative humidity (in the laboratory)

$S \quad$ constant in Sutherland's formula for $\mu$

$S_{p} \quad$ parachute inflated projected area

$S_{0} \quad$ parachute nominal area (used as the reference area for $C_{D}$ )

$T \quad$ temperature (in the laboratory)

$U \quad$ fictitious freestream airspeed

$u \quad$ permeability

$u_{\text {Avg }} \quad$ average permeability

$u_{\text {Max }} \quad$ maximum permeability

$u_{\text {Min }} \quad$ minimum permeability

$u_{R} \quad$ permeability range, $u_{\mathrm{Max}}-u_{\mathrm{Min}}$

$\beta \quad$ constant in Sutherland's formula for $\mu$

$\Delta p \quad$ differential pressure

$\lambda_{g} \quad$ parachute geometric porosity

$\lambda_{T} \quad$ parachute total porosity; the additional subscripts $M 1$ and $M 2$ are added to $\lambda_{T}$ when necessary to denote which method was used in its calculation

$\mu \quad$ coefficient of viscosity

$\rho \quad$ fluid density

DGB Disk-Gap-Band (parachute type)

MSL Mars Science Laboratory

PIA Parachute Industry Association

PST Pacific Standard Time

TDT Transonic Dynamics Tunnel 


\section{Introduction}

Recently, a wind tunnel test of subscale model parachutes was conducted at the NASA Langley Research Center Transonic Dynamics Tunnel (TDT) (ref. 1). To quantify the effect of fabric permeability $^{1}$ on the parachute's aerodynamic characteristics, subscale model parachutes of nominally identical geometries were fabricated from each of two fabrics. These two fabrics had very different permeability characteristics (i.e., permeability values at given differential pressures). The permeabilities of both fabrics were needed over a wide range of differential pressures to fully exploit the results of the wind tunnel test.

This technical memorandum describes tests conducted to obtain the needed fabric permeability data. Using these data, the effective porosities of the fabrics are calculated and mathematically modeled. These mathematical models are then applied to the determination of the parachute's total porosity and evaluation of the effect of fabric permeability on the parachute's drag coefficient.

\section{Permeability Testing}

\subsection{Fabrics}

The two parachute fabrics used in the permeability testing were PIA-C-7020D Type I and PIA-C-44378D Type I as described by Parachute Industry Association (PIA) specifications (refs. 2 and 3, respectively). Both fabrics were woven from nylon fibers. Key specification properties of these two fabrics are given in table 1.

Table 1. Key specification properties of the test fabrics.

\begin{tabular}{|c|c|c|c|}
\hline Fabric & Weave & Areal Weight (Max) & Permeability \\
\hline PIA-C-7020D Type I & Rip Stop & $\begin{array}{l}1.10 \mathrm{oz} / \mathrm{yd}^{2} \\
37.3 \mathrm{~g} / \mathrm{m}^{2}\end{array}$ & $\begin{array}{c}100 \pm 20 \mathrm{ft}^{3} / \mathrm{ft}^{2} / \mathrm{min} \\
50.8 \pm 10.2 \mathrm{~cm}^{3} / \mathrm{cm}^{2} / \mathrm{s}\end{array}$ \\
\hline PIA-C-44378D Type I & Rip Stop & $\begin{array}{l}1.20 \mathrm{oz} / \mathrm{yd}^{2} \\
40.7 \mathrm{~g} / \mathrm{m}^{2}\end{array}$ & $\begin{array}{c}0.5-5.0 \mathrm{ft}^{3} / \mathrm{ft}^{2} / \mathrm{min} \\
0.25-2.5 \mathrm{~cm}^{3} / \mathrm{cm}^{2} / \mathrm{s}\end{array}$ \\
\hline
\end{tabular}

Specification properties from references 2 (PIA-C-7020D Type I fabric) and 3 (PIA-C-44378D Type I fabric). Permeability values when tested per ASTM International Test Method D737 (ref. 4) at a differential pressure of 0.5 inch of water $(2.60 \mathrm{psf}, 124 \mathrm{~Pa})$.

\subsection{Test Instrument}

Testing was conducted in air using a Textest Instruments FX 3300 Labotester III Air Permeability Tester (see figure 1). This instrument was located at the Quality Assurance Laboratory of the Escape, Parachute and Crashworthy Division at the Naval Air Warfare Center Weapons Division in China Lake, California. At the time testing was conducted, this instrument had a valid calibration. The sample test region was circular with a diameter of 2.75 in $(6.99 \mathrm{~cm})$

\footnotetext{
${ }^{1}$ Fabric permeability is the flow-through volume of air per area per time.
} 
and an area of $5.94 \mathrm{in}^{2}\left(38.3 \mathrm{~cm}^{2}\right)$. Operation of this instrument involved selecting the differential pressure (in integer increments of $\mathrm{Pa}$ ) and measuring the resultant permeability. The instrument manufacturer stated that the differential pressure and permeability measurements have an expected uncertainty of \pm 5 percent for differential pressures less than $2.05 \mathrm{psf}(98 \mathrm{~Pa}$ ), and \pm 3 percent at higher differential pressures.

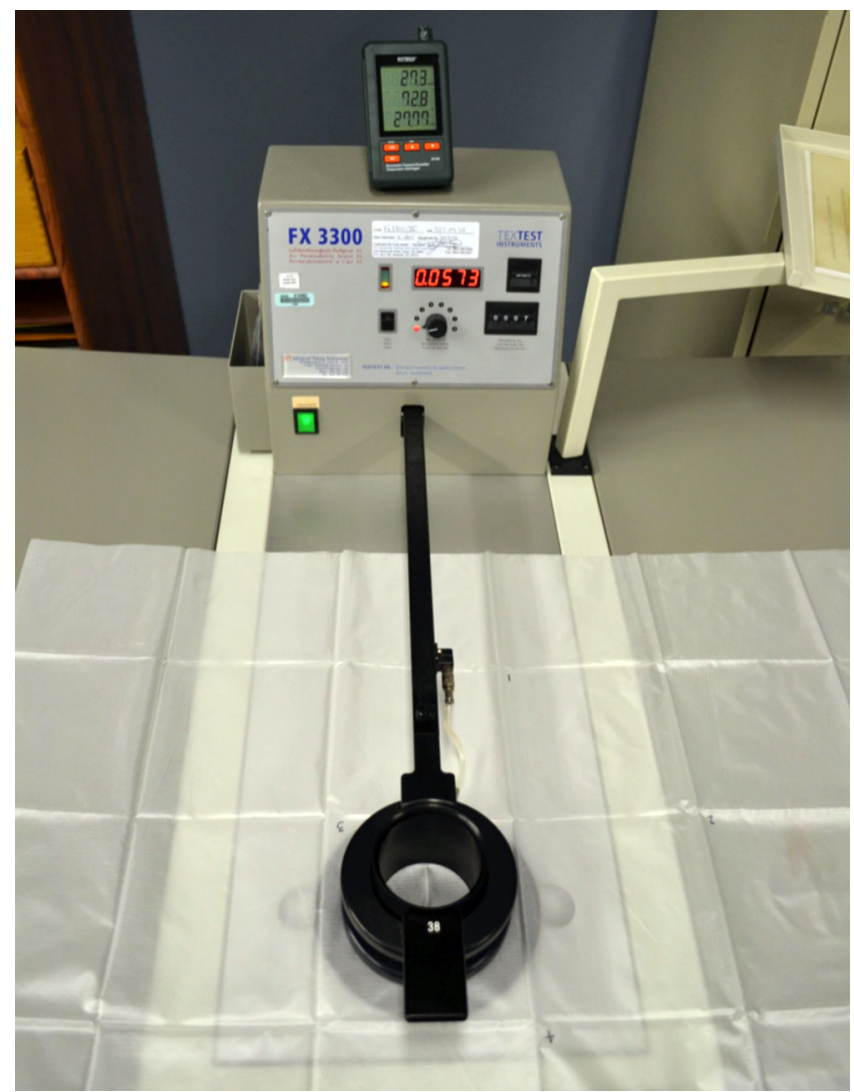

Figure 1. Test instrument. Portion of fabric being tested is inside circular clamp.

\subsection{Test Samples}

The two fabrics used in the permeability testing were from the same lots as those used to fabricate the model parachutes used during the wind tunnel test described in reference 1.

For each fabric, a single piece of approximately $1 \mathrm{yd}^{2}\left(0.8 \mathrm{~m}^{2}\right)$ in area was provided to the testing laboratory. Five samples were selected from each of these pieces of fabric. The locations of the samples, and the numbering scheme used to identify them, are shown in figure 2. Each square in this figure was approximately $6.5 \times 6.5$ in $(16.5 \times 16.5 \mathrm{~cm})$. Placing samples near the fabric edges was avoided. The samples were not cut from the fabric provided; the test instrument allowed for testing without cutting the fabric. Figure 1 shows a sample in place for testing. 


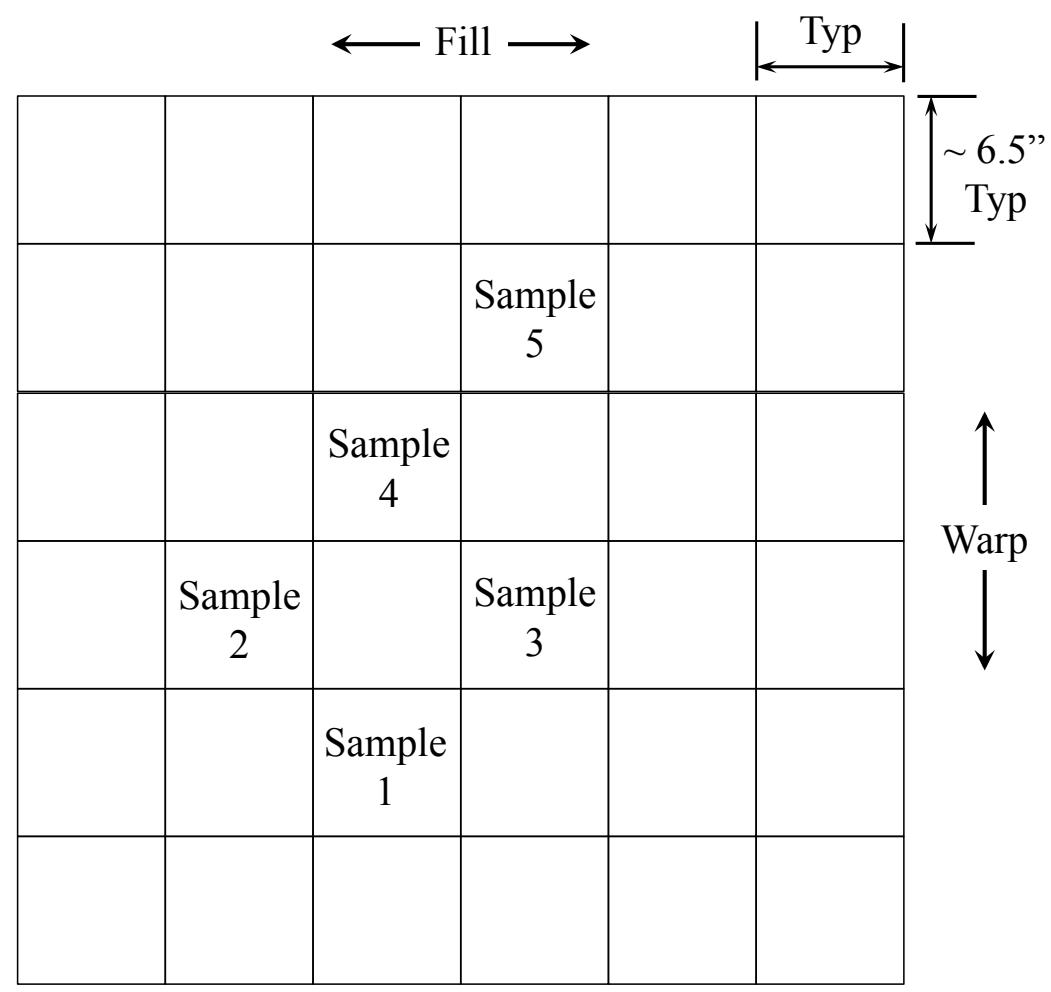

Figure 2. Position of samples on fabrics.

\section{$2.4 \quad$ Test Matrix}

The test matrix is given in table 2. Each sample was tested at ten values of differential pressure from $0.146 \mathrm{psf}(7 \mathrm{~Pa})$ to $25 \mathrm{psf}(1197 \mathrm{~Pa})$. The differential pressure range was selected to satisfy the analysis needs of the parachute data in reference 1 . Testing for each sample was conducted in the order shown in table 2, always starting and concluding with the lowest differential pressure $(0.146 \mathrm{psf}, 7 \mathrm{~Pa})$. Repeating the first differential pressure at the end of the test for each sample provided data for partial evaluation of the repeatability of the results. The test sequence for Samples 1 and 5 were the same; this was done to evaluate sample-to-sample (i.e., location) variation in the results. Note that, except for the last test in the test sequence, the differential pressures used for Samples 1 and 5 increased monotonically. For Samples 2-4, the test sequence of differential pressure values between the first and last test were randomized in an attempt to evaluate the effect of test sequence. Following the completion of the tests listed in table 2, replicate tests of Sample 3 (both fabric types) and Sample 4 (PIA-C-44378D Type I only) were conducted to evaluate the effect of test-to-test variation. 
Table 2. Test matrix.

Customary Units

\begin{tabular}{|c|r|r|r|r|r|r|r|r|r|r|r|}
\hline Sample & \multicolumn{10}{|c|}{ Differential Pressure, $\Delta p(\mathrm{psf})$} \\
\hline 1 & 0.146 & 0.251 & 0.501 & 0.752 & 1.003 & 2.047 & 3.008 & 5.994 & 12.009 & 25.000 & 0.146 \\
\hline 2 & 0.146 & 1.003 & 3.008 & 0.251 & 0.501 & 5.994 & 25.000 & 12.009 & 0.752 & 2.047 & 0.146 \\
\hline 3 & 0.146 & 0.251 & 2.047 & 12.009 & 5.994 & 0.752 & 25.000 & 1.003 & 0.501 & 3.008 & 0.146 \\
\hline 4 & 0.146 & 3.008 & 1.003 & 25.000 & 2.047 & 0.251 & 5.994 & 0.752 & 0.501 & 12.009 & 0.146 \\
\hline 5 & 0.146 & 0.251 & 0.501 & 0.752 & 1.003 & 2.047 & 3.008 & 5.994 & 12.009 & 25.000 & 0.146 \\
\hline
\end{tabular}

SI Units

\begin{tabular}{|c|r|r|r|r|r|r|r|r|r|r|r|}
\hline Sample & \multicolumn{10}{|c|}{ Differential Pressure, $\Delta p(\mathrm{~Pa})$} \\
\hline 1 & 7.00 & 12.00 & 24.00 & 36.00 & 48.00 & 98.00 & 144.00 & 287.00 & 575.00 & 1197.00 & 7.00 \\
\hline 2 & 7.00 & 48.00 & 144.00 & 12.00 & 24.00 & 287.00 & 1197.00 & 575.00 & 36.00 & 98.00 & 7.00 \\
\hline 3 & 7.00 & 12.00 & 98.00 & 575.00 & 287.00 & 36.00 & 1197.00 & 48.00 & 24.00 & 144.00 & 7.00 \\
\hline 4 & 7.00 & 144.00 & 48.00 & 1197.00 & 98.00 & 12.00 & 287.00 & 36.00 & 24.00 & 575.00 & 7.00 \\
\hline 5 & 7.00 & 12.00 & 24.00 & 36.00 & 48.00 & 98.00 & 144.00 & 287.00 & 575.00 & 1197.00 & 7.00 \\
\hline
\end{tabular}

\section{$2.5 \quad$ Test Procedure}

Twenty-four hours prior to testing, the fabric pieces were unfolded and set aside so that they could reach equilibrium with the laboratory's environmental condition (which were almost constant). Testing was conducted at the laboratory's temperature and relative humidity. Each sample was installed on the test instrument as shown in figure 1. Testing proceeded in the sequence shown in table 2 by setting the desired differential pressure and recording the measured permeability. A given sample was tested in the specified differential pressure sequence without being reset (i.e., removed and reinstalled) in the test instrument. After each test (i.e., permeability measurement at a specific differential pressure) the differential pressure was reduced to zero and the sample was allowed to "rest" for approximately four minutes before testing at the next value of the differential pressure.

\subsection{Data Acquisition}

The following quantities were recorded during testing:

- Fabric

- Sample number

- Date and time of test

- Atmospheric (upstream) pressure (in the laboratory), $p$ (in. $\mathrm{Hg}$ )

- Atmospheric temperature (in the laboratory), $T\left({ }^{\circ} \mathrm{F}\right)$

- Relative humidity (in the laboratory), $R H(\%)$

- Differential pressure, $\Delta p(\mathrm{~Pa})$

- Permeability, $u\left(\mathrm{ft}^{3} / \mathrm{ft}^{2} / \mathrm{min}\right.$ or $\left.\mathrm{cm}^{3} / \mathrm{cm}^{2} / \mathrm{s}\right)$ 


\section{Permeability Test Results}

The permeability results are shown graphically in figures 3 and 4, and in summary in tables 3 and 4 (for PIA-C-7020D Type I and PIA-C-44378D Type I fabrics, respectively). A complete set of permeability results is presented in tables in Appendix A.

Several observations can be made from these results:

1. The permeability of both fabrics increases with differential pressure over the range of differential pressures used in the test.

2. The permeability of the PIA-C-7020D Type I fabric is much greater $(>25 \mathrm{X})$ than that of the PIA-C-44378D Type I fabric.

3. Both fabrics met their permeability specifications (see figures $3 b$ and $4 b$ ).

4. The variation in the permeability results at a given differential pressure was significant. For the PIA-C-7020D Type I fabric the permeability range divided by the average value was in the range from 0.15 to 0.18 over the tested differential pressure range (see table 3 ). For the PIA-C-44378D Type I fabric the permeability range divided by the average value was in the range from 0.25 to 0.30 over the tested differential pressure range (see table 4).

5. For a given fabric, the principal source of variation in the results seemed to be the sample location within the piece of fabric provided for testing. This observation was supported by the difference in the results between Samples 1 and 5, which were tested using the same test sequence (see table 2). The test sequence did not seem to be a significant source of the observed variation. Additional replicate testing (see Appendix B) indicated that test-to-test variation was not the principal source of the variation. 
$\longrightarrow$ Sample $1 \rightarrow$ - Sample $2 \quad \rightarrow-$ Sample $3 \quad$ - $\rightarrow$--Sample $4 \quad \cdots--$ Sample 5

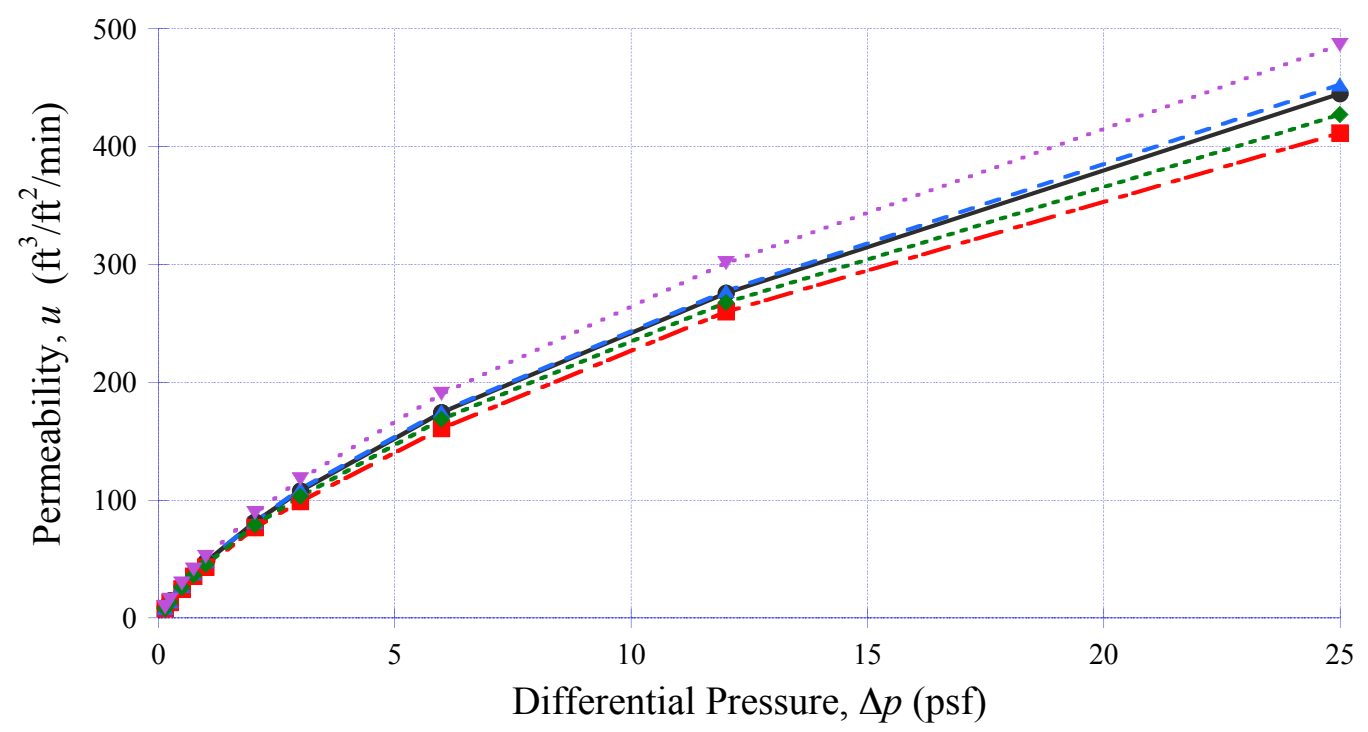

(a) Full differential pressure range: 0.146-25 psf (7-1197 $\mathrm{Pa})$.

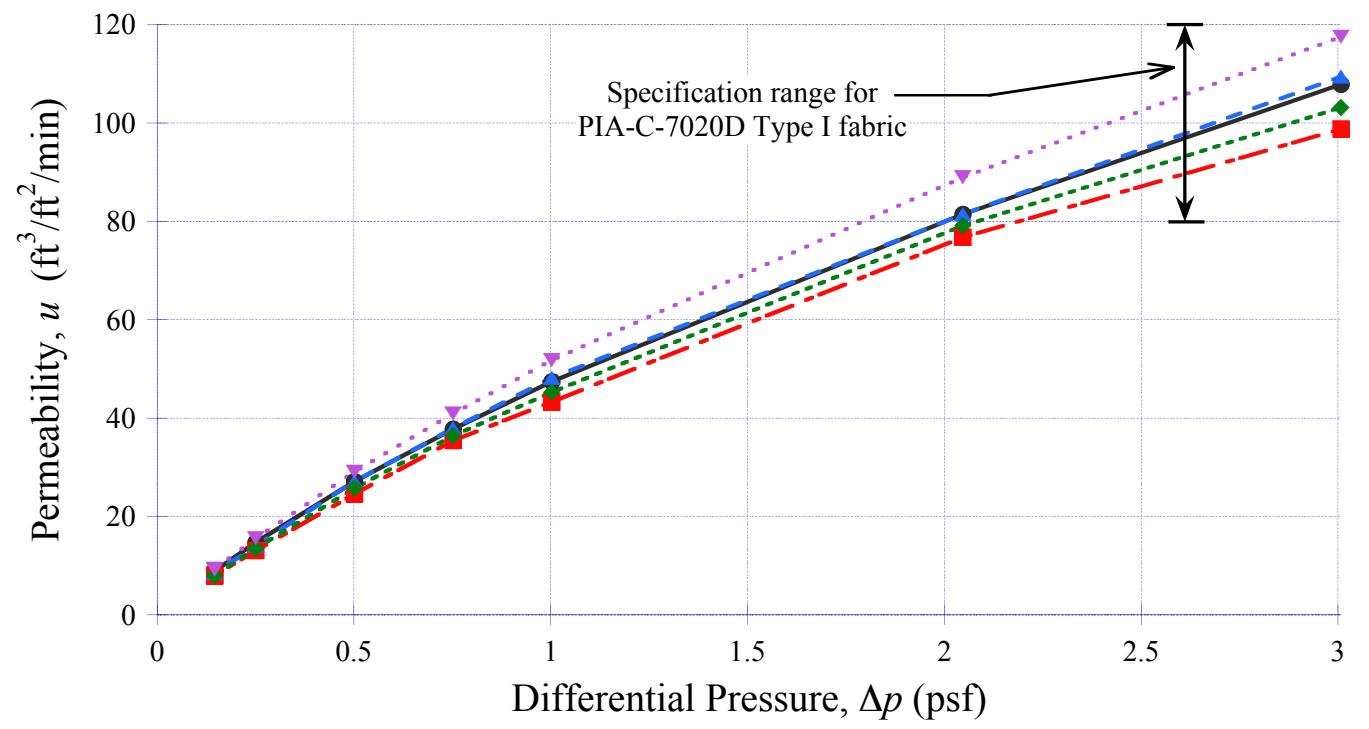

(b) Close up of the lower differential pressure range: $0.146-3$ psf (7-143.6 Pa).

Figure 3. Permeability results for PIA-C-7020D Type I fabric. 


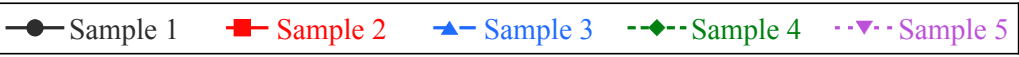

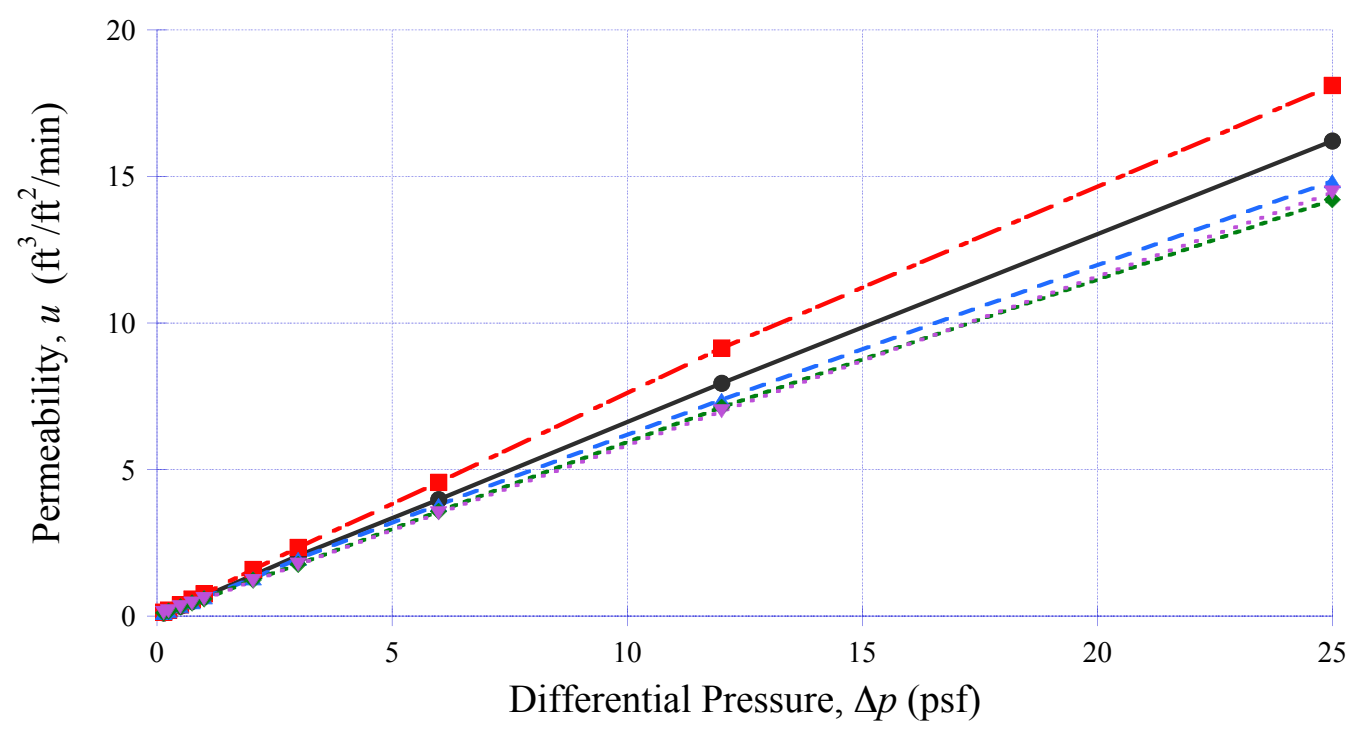

(a) Full differential pressure range: $0.146-25$ psf (7-1197 Pa).

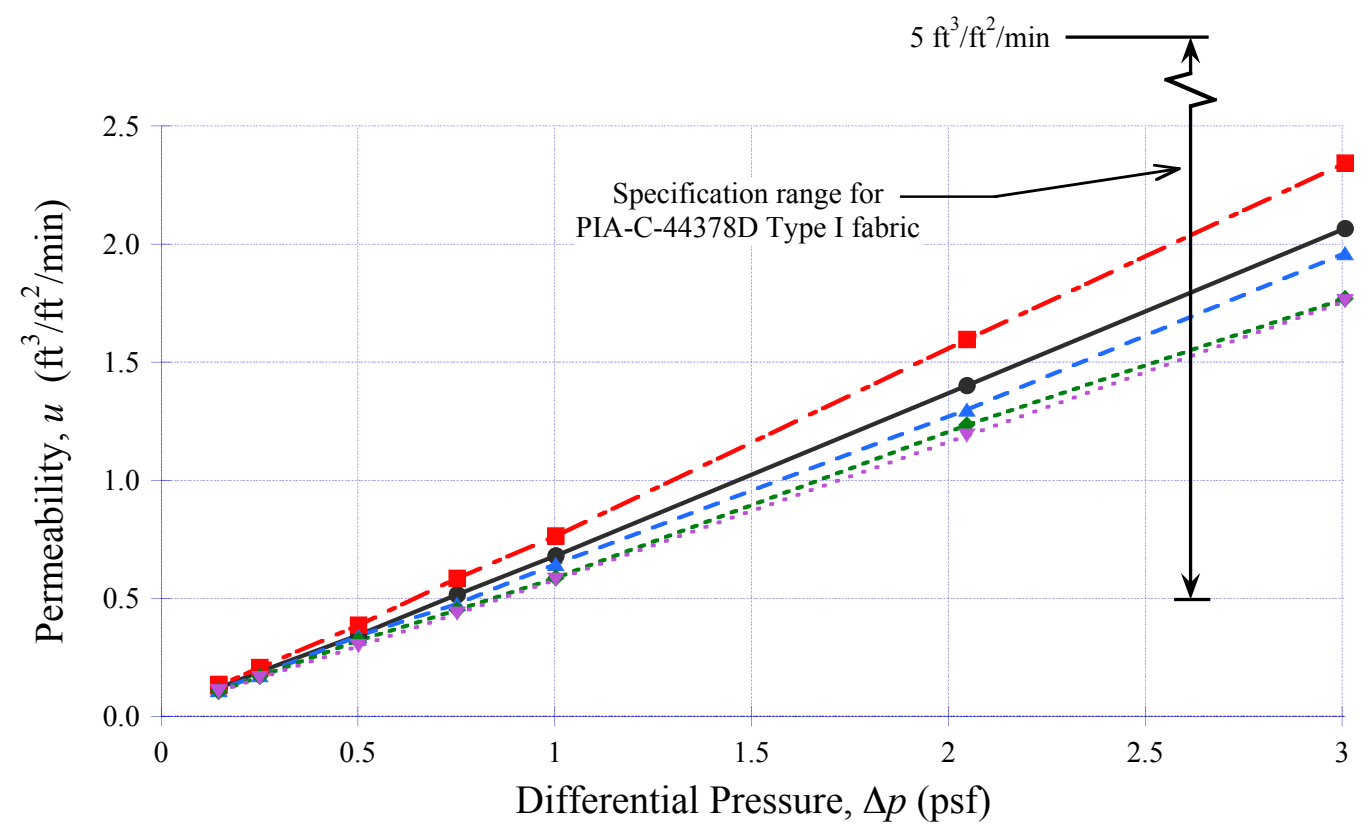

(b) Close up of the lower differential pressure range: 0.146-3 psf (7-143.6 Pa).

Figure 4. Permeability results for PIA-C-44378D Type I fabric. 
Table 3. Summary of permeability results for PIA-C-7020D Type I fabric.

\begin{tabular}{|c|c|c|c|c|c|c|c|c|c|c|}
\hline $\begin{array}{l}\text { Diff. } \\
\text { Pres. } \\
\Delta p\end{array}$ & $\begin{array}{c}\text { Avg. } \\
\text { Permeability } \\
u_{\text {Avg }}\end{array}$ & $\begin{array}{c}\text { Min } \\
\text { Permeability } \\
u_{\text {Min }}\end{array}$ & $\begin{array}{c}\text { Max } \\
\text { Permeability } \\
u_{\mathrm{Max}}\end{array}$ & $\begin{array}{c}\text { Permeability } \\
\text { Range } \\
u_{R} \\
=u_{\mathrm{Max}}-u_{\mathrm{Min}}\end{array}$ & $\begin{array}{c}\text { Diff. } \\
\text { Pres. } \\
\Delta p\end{array}$ & $\begin{array}{c}\text { Avg. } \\
\text { Permeability } \\
u_{\text {Avg }}\end{array}$ & $\begin{array}{c}\text { Min } \\
\text { Permeability } \\
u_{\text {Min }}\end{array}$ & $\begin{array}{c}\text { Max } \\
\text { Permeability } \\
u_{\operatorname{Max}}\end{array}$ & $\begin{array}{c}\text { Permeability } \\
\text { Range } \\
u_{R} \\
=u_{\mathrm{Max}}-u_{\mathrm{Min}}\end{array}$ & $\begin{array}{c}\text { Range/Avg. } \\
\text { Permeability } \\
u_{R} / u_{\text {Avg }}\end{array}$ \\
\hline (psf) & \multicolumn{4}{|c|}{$\left(\mathrm{ft}^{3} / \mathrm{ft}^{2} / \mathrm{min}\right)$} & $(\mathrm{Pa})$ & \multicolumn{4}{|c|}{$\left(\mathrm{cm}^{3} / \mathrm{cm}^{2} / \mathrm{s}\right)$} & - \\
\hline 0.146 & 8.57 & 7.95 & 9.41 & 1.46 & 7.0 & 4.36 & 4.04 & 4.78 & 0.74 & 0.17 \\
\hline 0.251 & 14.21 & 13.13 & 15.55 & 2.42 & 12.0 & 7.22 & 6.67 & 7.90 & 1.23 & 0.17 \\
\hline 0.501 & 26.77 & 24.61 & 29.13 & 4.53 & 24.0 & 13.60 & 12.50 & 14.80 & 2.30 & 0.17 \\
\hline 0.752 & 37.72 & 35.43 & 40.94 & 5.51 & 36.0 & 19.16 & 18.00 & 20.80 & 2.80 & 0.15 \\
\hline 1.003 & 47.20 & 43.31 & 51.77 & 8.46 & 48.0 & 23.98 & 22.00 & 26.30 & 4.30 & 0.18 \\
\hline 2.047 & 81.57 & 76.77 & 88.98 & 12.20 & 98.0 & 41.44 & 39.00 & 45.20 & 6.20 & 0.15 \\
\hline 3.008 & 107.36 & 98.82 & 117.52 & 18.70 & 144.0 & 54.54 & 50.20 & 59.70 & 9.50 & 0.17 \\
\hline 5.994 & 173.90 & 160.83 & 190.16 & 29.33 & 287.0 & 88.34 & 81.70 & 96.60 & 14.90 & 0.17 \\
\hline 12.009 & 276.38 & 259.84 & 301.18 & 41.34 & 575.0 & 140.40 & 132.00 & 153.00 & 21.00 & 0.15 \\
\hline 25.000 & 444.49 & 411.42 & 486.22 & 74.80 & 1197.0 & 225.80 & 209.00 & 247.00 & 38.00 & 0.17 \\
\hline
\end{tabular}

Table 4. Summary of permeability results for PIA-C-44378D Type I fabric.

\begin{tabular}{|c|c|c|c|c|c|c|c|c|c|c|}
\hline $\begin{array}{l}\text { Diff. } \\
\text { Pres. } \\
\Delta p\end{array}$ & $\begin{array}{c}\text { Avg. } \\
\text { Permeability } \\
u_{\text {Avg }}\end{array}$ & $\begin{array}{c}\text { Min } \\
\text { Permeability } \\
u_{\text {Min }}\end{array}$ & $\begin{array}{c}\text { Max } \\
\text { Permeability } \\
u_{\mathrm{Max}}\end{array}$ & $\begin{array}{c}\text { Permeability } \\
\text { Range } \\
u_{R} \\
=u_{\mathrm{Max}}-u_{\mathrm{Min}}\end{array}$ & $\begin{array}{c}\text { Diff. } \\
\text { Pres. } \\
\Delta p\end{array}$ & $\begin{array}{c}\text { Avg. } \\
\text { Permeability } \\
u_{\text {Avg }}\end{array}$ & $\begin{array}{c}\text { Min } \\
\text { Permeability } \\
u_{\text {Min }}\end{array}$ & $\begin{array}{c}\text { Max } \\
\text { Permeability } \\
u_{\mathrm{Max}}\end{array}$ & $\begin{array}{c}\text { Permeability } \\
\text { Range } \\
u_{R} \\
=u_{\mathrm{Max}}-u_{\mathrm{Min}}\end{array}$ & $\begin{array}{c}\text { Range/Avg. } \\
\text { Permeability } \\
u_{R} / u_{\text {Avg }}\end{array}$ \\
\hline (psf) & \multicolumn{4}{|c|}{$\left(\mathrm{ft}^{3} / \mathrm{ft}^{2} / \mathrm{min}\right)$} & $(\mathrm{Pa})$ & \multicolumn{4}{|c|}{$\left(\mathrm{cm}^{3} / \mathrm{cm}^{2} / \mathrm{s}\right)$} & - \\
\hline 0.146 & 0.115 & 0.103 & 0.135 & 0.032 & 7.0 & 0.0586 & 0.0525 & 0.0686 & 0.0161 & 0.27 \\
\hline 0.251 & 0.180 & 0.162 & 0.207 & 0.045 & 12.0 & 0.0916 & 0.0822 & 0.1050 & 0.0228 & 0.25 \\
\hline 0.501 & 0.338 & 0.297 & 0.386 & 0.089 & 24.0 & 0.1716 & 0.1510 & 0.1960 & 0.0450 & 0.26 \\
\hline 0.752 & 0.493 & 0.435 & 0.585 & 0.150 & 36.0 & 0.2502 & 0.2210 & 0.2970 & 0.0760 & 0.30 \\
\hline 1.003 & 0.651 & 0.579 & 0.764 & 0.185 & 48.0 & 0.3308 & 0.2940 & 0.3880 & 0.0940 & 0.28 \\
\hline 2.047 & 1.344 & 1.189 & 1.596 & 0.407 & 98.0 & 0.6828 & 0.6040 & 0.8110 & 0.2070 & 0.30 \\
\hline 3.008 & 1.980 & 1.758 & 2.343 & 0.585 & 144.0 & 1.0058 & 0.8930 & 1.1900 & 0.2970 & 0.30 \\
\hline 5.994 & 3.886 & 3.504 & 4.567 & 1.063 & 287.0 & 1.9740 & 1.7800 & 2.3200 & 0.5400 & 0.27 \\
\hline 12.009 & 7.720 & 6.988 & 9.154 & 2.165 & 575.0 & 3.9220 & 3.5500 & 4.6500 & 1.1000 & 0.28 \\
\hline 25.000 & 15.567 & 14.213 & 18.110 & 3.898 & 1197.0 & 7.9080 & 7.2200 & 9.2000 & 1.9800 & 0.25 \\
\hline
\end{tabular}

Note: In tables 3 and 4 above, data for all samples at a specific differential pressure (original tests only, not including replicates) were used to determine the average, minimum, maximum, and range of permeabilities. 


\section{Effective Porosity Test Results, Modeling, and Application}

To make full use of the results presented in the previous section, the fabric permeability needs to be transformed to a quantity that allows for the determination of its contribution to the parachute's porosity. This transformation is accomplished by calculating an effective porosity from the fabric permeability results. The approach followed herein to obtain, model, and apply effective porosity closely follows that presented by Lingard and Underwood in reference 5 and in unpublished lecture notes by Lingard in reference 6 .

\subsection{Effective Porosity Test Results}

An effective porosity, $c_{e}$, can be defined as

$$
c_{e}=\frac{u}{U}
$$

where $u$ is the fabric permeability (interpreted here as an airspeed through the fabric), and $U$ is a fictitious freestream airspeed ${ }^{2}$ related to freestream dynamic pressure. The value of $U$ is determined from the differential pressure across the fabric,

$$
\Delta p=\frac{1}{2} \rho U^{2}
$$

where $\rho$ is the density of the fluid. In the present analyses, the fluid is considered to be incompressible. From theoretical considerations, $c_{e}$ can be modeled as a function of the unit Reynolds number $\hat{R} e$ using $U$ as the reference airspeed:

$$
\hat{R} e=\frac{\rho U}{\mu}
$$

where $\mu$ is the coefficient of viscosity (dynamic viscosity) of the fluid.

From the permeability results already presented, $c_{e}$ and $\hat{R} e$ were calculated for both fabrics from equations (1)-(3) using the following additional equations and constants: the equation of state and the gas constant for air, $R$, (ref. 8)

$$
\rho=\frac{p}{R T}
$$

\footnotetext{
${ }^{2}$ See reference 7, Section III - The Concept of Effective Porosity, pp. 10-12.
} 


$$
R=1716.57 \frac{\mathrm{ft} \bullet \mathrm{lb}}{\mathrm{slug} \bullet{ }^{\circ} \mathrm{R}} \quad\left(287.053 \frac{\mathrm{N} \bullet \mathrm{m}}{\mathrm{kg} \bullet \mathrm{K}}\right)
$$

and Sutherland's formula for $\mu$, and its constants $\beta$ and $S$ for air (ref. 8)

$$
\begin{gathered}
\mu=\frac{\beta T^{\frac{3}{2}}}{S+T} \\
\beta=1.458 \cdot 10^{-6} \frac{\mathrm{kg}}{\mathrm{m} \cdot \mathrm{s} \cdot \mathrm{K}^{\frac{1}{2}}} \\
S=110.4 \mathrm{~K}
\end{gathered}
$$

The value of $\mu$ was calculated in SI units $\left(\mathrm{N} \cdot \mathrm{s} / \mathrm{m}^{2}\right)$ using the equation and constants from reference 8 and then converted to U.S. Customary Units $\left(\mathrm{lb} \bullet \mathrm{s} / \mathrm{ft}^{2}\right)$.

The original permeability results (i.e., those presented in Appendix A) were processed to yield $c_{e}$ vs. $\hat{R} e$. These effective porosity results are shown by symbols in figures 5 and 6 , and in summary (averaging points at the same value of $\Delta p$ ) in table 5 for both PIA-C-7020D Type I and PIA-C-44378D Type I fabrics. A complete set of effective porosity results are given in tables in Appendix C.

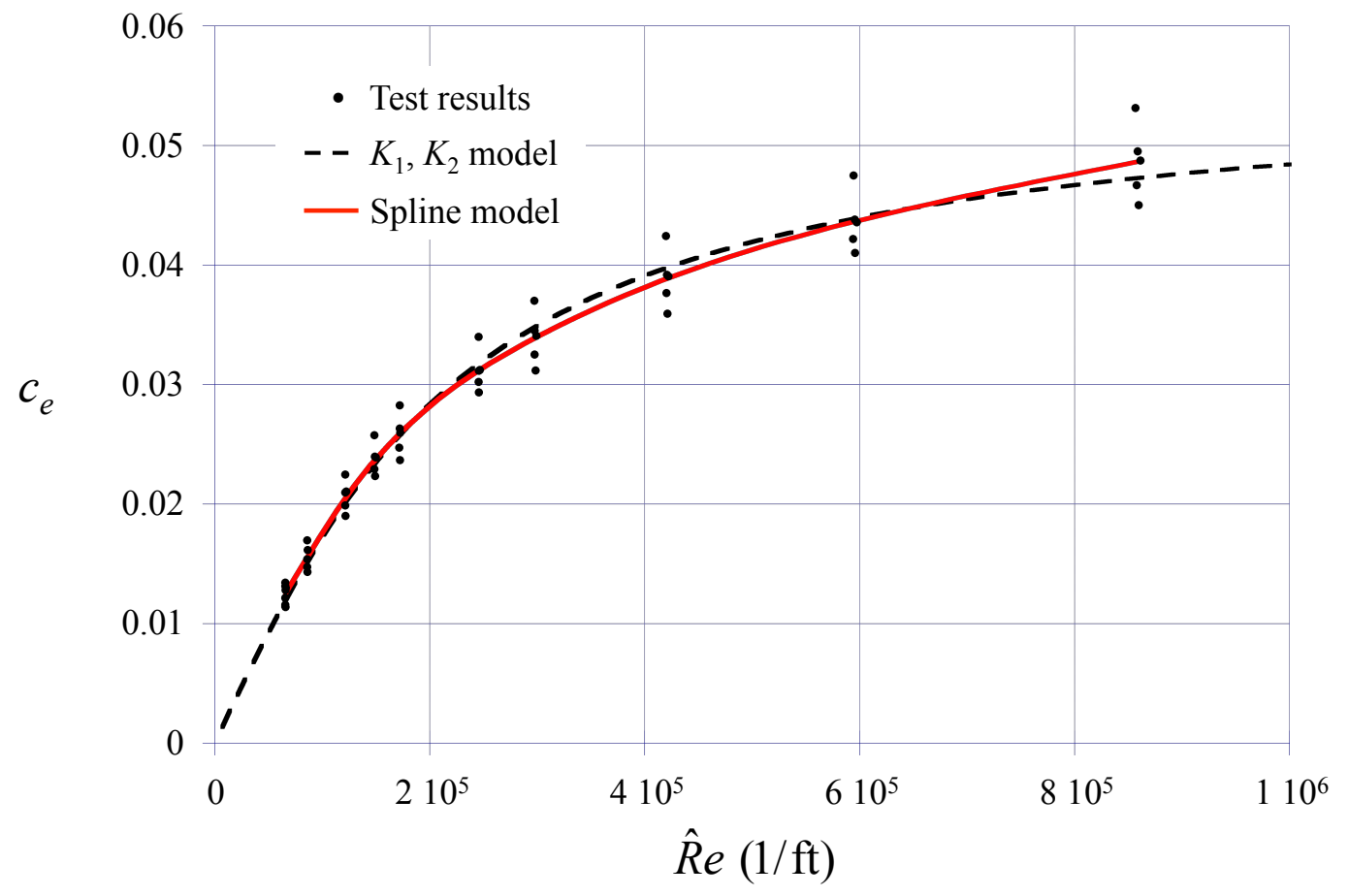

Figure 5. Effective porosity results and models for PIA-C-7020D Type I fabric. 


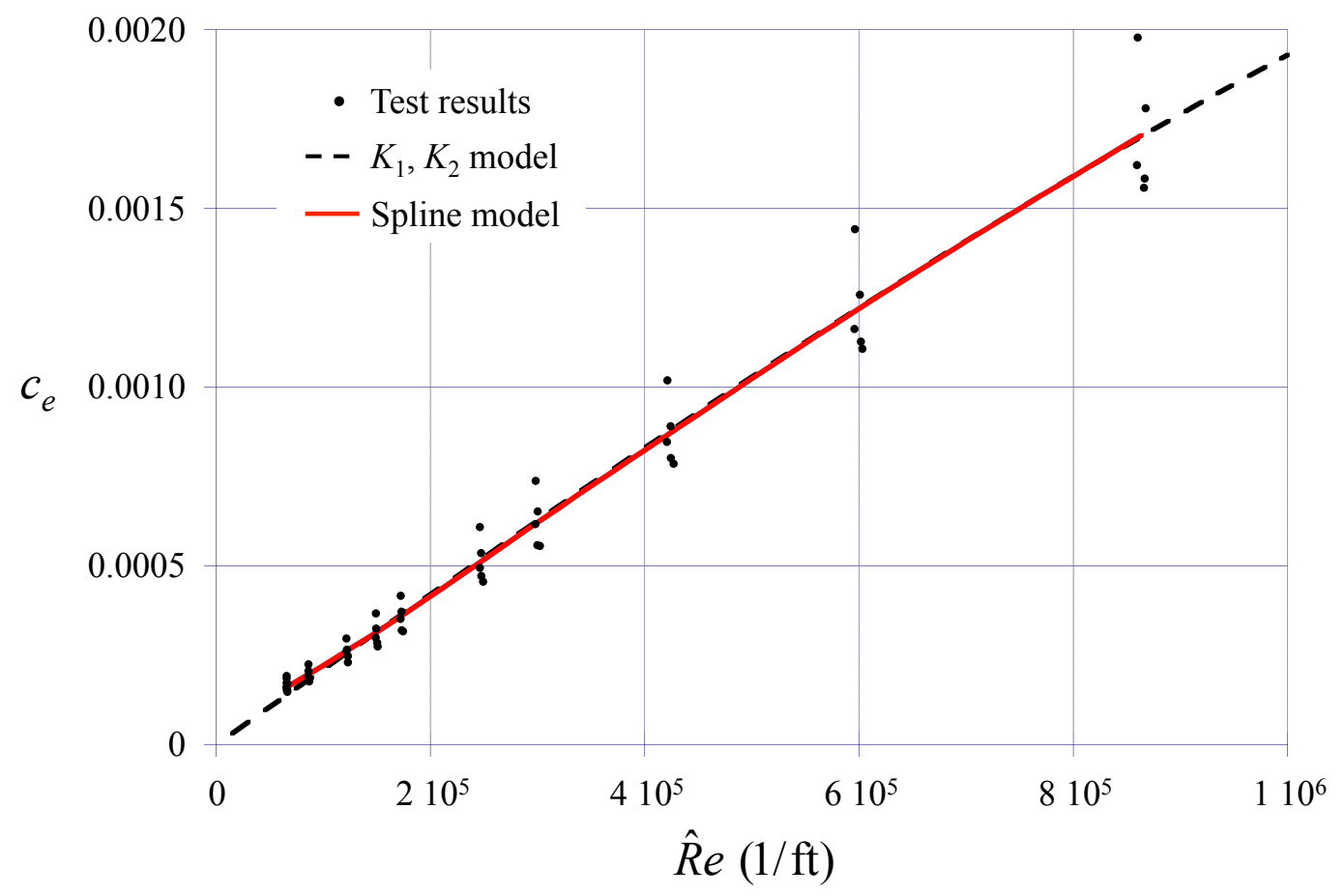

Figure 6. Effective porosity results and models for PIA-C-44378D Type I fabric.

Table 5. Effective porosity results and spline model.

\begin{tabular}{|c|c|c|c|c|c|c|c|}
\hline \multicolumn{4}{|c|}{ PIA-C-7020D Type I Fabric } & \multicolumn{4}{|c|}{ PIA-C-44378D Type I Fabric } \\
\hline \multicolumn{2}{|c|}{$\hat{R} e_{\text {Avg }}$} & \multirow{2}{*}{$\begin{array}{c}c_{e, \text { Avg }} \\
\text { Avg. Test } \\
\text { Results }\end{array}$} & \multirow{2}{*}{$\begin{array}{c}c_{e} \\
\text { Spline } \\
\text { Model }\end{array}$} & \multicolumn{2}{|c|}{$\hat{R} e_{\text {Avg }}$} & \multirow{2}{*}{$\begin{array}{c}c_{e, \mathrm{Avg}} \\
\text { Avg. Test } \\
\text { Results }\end{array}$} & \multirow{2}{*}{$\begin{array}{c}c_{e} \\
\text { Spline } \\
\text { Model }\end{array}$} \\
\hline$(1 / \mathrm{ft})$ & $(1 / \mathrm{m})$ & & & $(1 / \mathrm{ft})$ & $(1 / \mathrm{m})$ & & \\
\hline $6.572 \mathrm{E}+04$ & $2.156 \mathrm{E}+05$ & 0.01227 & 0.01248 & $6.604 \mathrm{E}+04$ & $2.167 \mathrm{E}+05$ & 0.0001652 & 0.0001602 \\
\hline $8.609 \mathrm{E}+04$ & $2.825 \mathrm{E}+05$ & 0.01554 & 0.01554 & $8.645 \mathrm{E}+04$ & $2.836 \mathrm{E}+05$ & 0.0001972 & 0.0001971 \\
\hline $1.217 \mathrm{E}+05$ & $3.992 \mathrm{E}+05$ & 0.02070 & 0.02048 & $1.223 \mathrm{E}+05$ & $4.012 \mathrm{E}+05$ & 0.0002612 & 0.0002629 \\
\hline $1.490 \mathrm{E}+05$ & $4.889 \mathrm{E}+05$ & 0.02381 & 0.02366 & $1.498 \mathrm{E}+05$ & $4.915 \mathrm{E}+05$ & 0.0003110 & 0.0003150 \\
\hline $1.722 \mathrm{E}+05$ & $5.651 \mathrm{E}+05$ & 0.02581 & 0.02591 & $1.730 \mathrm{E}+05$ & $5.676 \mathrm{E}+05$ & 0.0003562 & 0.0003603 \\
\hline $2.459 \mathrm{E}+05$ & $8.069 \mathrm{E}+05$ & 0.03121 & 0.03122 & $2.473 \mathrm{E}+05$ & $8.114 \mathrm{E}+05$ & 0.0005146 & 0.0005126 \\
\hline $2.981 \mathrm{E}+05$ & $9.780 \mathrm{E}+05$ & 0.03388 & 0.03392 & $2.997 \mathrm{E}+05$ & $9.834 \mathrm{E}+05$ & 0.0006253 & 0.0006214 \\
\hline $4.208 \mathrm{E}+05$ & $1.380 \mathrm{E}+06$ & 0.03887 & 0.03887 & $4.235 \mathrm{E}+05$ & $1.390 \mathrm{E}+06$ & 0.0008696 & 0.0008716 \\
\hline $5.954 \mathrm{E}+05$ & $1.953 \mathrm{E}+06$ & 0.04364 & 0.04364 & $5.994 \mathrm{E}+05$ & $1.967 \mathrm{E}+06$ & 0.0012205 & 0.0012192 \\
\hline $8.589 \mathrm{E}+05$ & $2.818 \mathrm{E}+06$ & 0.04864 & 0.04864 & $8.638 \mathrm{E}+05$ & $2.834 \mathrm{E}+06$ & 0.0017049 & 0.0017054 \\
\hline
\end{tabular}

Notes: This table provides the average unit Reynolds number, $\hat{R} e_{\text {Avg }}$, and the average effective porosity, $c_{e, \text { Avg. }}$ These averages were calculated for each of the ten differential pressures used in the permeability tests. The data in this table are listed in order of increasing $\hat{R} e_{\text {Avg }}$. 


\subsection{Effective Porosity Modeling}

In reference 5 , the following equation is proposed to model the relationship between $c_{e}$ and $\hat{R} e$

$$
c_{e}=\frac{-K_{2}}{2 K_{1} \hat{R} e}+\sqrt{\left(\frac{K_{2}}{2 K_{1} \hat{R} e}\right)^{2}+\frac{1}{2 K_{1}}}
$$

where $K_{1}$ and $K_{2}$ are constants dependent only on the specific fabric. Nonlinear least-squares fits of the porosity data presented in Appendix $C$ were performed using equation (6). The values of $K_{1}$ and $K_{2}$ obtained from these fits are given in table 6 . The curves created using these fits are presented graphically in figures 5 and 6 as black dashed lines labeled " $K_{1}, K_{2}$ model " (note that in these figures the fits are shown extrapolated for values of $\hat{R} e$ beyond the available porosity test data). As can be seen from figures 5 and 6, equation (6) with appropriate values of $K_{1}$ and $K_{2}$ provide good fits to the porosity results, except for the lowest values of $\hat{R} e$ for the PIA-C-44378D Type I fabric.

Table 6. Fitted values of $K_{1}$ and $K_{2}$ for both fabrics.

\begin{tabular}{|l|c|c|c|}
\hline \multirow{2}{*}{ Fabric } & $K_{1}$ & \multicolumn{2}{|c|}{$K_{2}$} \\
\cline { 2 - 4 } & (dimensionless) & $(1 / \mathrm{ft})$ & $(1 / \mathrm{m})$ \\
\hline PIA-C-7020D Type I & $1.5881679 \mathrm{E}+02$ & $2.63019691 \mathrm{E}+06$ & $8.62925494 \mathrm{E}+06$ \\
\hline PIA-C-44378D Type I & $1.1303031 \mathrm{E}+04$ & $2.37148232 \mathrm{E}+08$ & $7.78045379 \mathrm{E}+08$ \\
\hline
\end{tabular}

Additional models are shown in figures 5 and 6 and presented numerically in table 5 . The values of $c_{e, \text { Avg }}$ and $\hat{R} e_{\text {Avg }}$ in table 5 were used to create spline models. These models attempted to fit the porosity results with a smooth curve that did not necessarily go through each point $\left(c_{e, \mathrm{Avg}}, \hat{R} e_{\mathrm{Avg}}\right)$. The spline models are shown as solid red lines in figures 5 and 6 . These spline models provide an alternative to the " $K_{1}, K_{2}$ model" defined by equation (6) and may be better models to the data in some intervals. Note, however, that the spline models are not suitable for extrapolation to values of $\hat{R} e$ other than those used to create them.

\subsection{Effective Porosity Application}

The total porosity of the parachute, $\lambda_{T}$, can be calculated using the equation

$$
\lambda_{T}=k \lambda_{g}+\left(1-\lambda_{g}\right) c_{e}
$$

where $\lambda_{g}$ is the geometric porosity of the parachute, and $k$ is the discharge coefficient with a value somewhere between 0.6 and $0.7 .^{3}$ In equation (7), the term $k \lambda_{g}$ is the contribution of geometric porosity of the parachute to $\lambda_{T}$, and the $\left(1-\lambda_{g}\right) c_{e}$ term is the contribution due to fabric

3 From the document by Lingard (ref. 6): "and $k$ the discharge coefficient, typically 0.6 to 0.7 . In the literature you will usually find total porosity incorrectly, but simply, defined as $\lambda_{T}=\lambda_{g}+c_{e}$. This fails to allow for the open areas in the material porosity element and assumes perfect discharge." 
permeability. To estimate $c_{e}$, an appropriate value of $\hat{R} e$ has to be determined for use in the porosity models described in the previous section. Solving equation (2) for $U$ and substituting the result into equation (3) yields

$$
\hat{R} e=\frac{\sqrt{2 \rho \Delta p}}{\mu}
$$

In equation (8), it is assumed that the flight condition is known and, thus, $\rho$ and $\mu$ are known. Thus, what remains to be done to calculate $\hat{R} e$ is to determine $\Delta p$. Two methods are presented here for calculating $\Delta p$. From reference 5:

$$
\Delta p=\frac{q C_{D} S_{0}}{S_{P}} \quad[\text { Method 1] }
$$

where $q$ is the dynamic pressure at the flight condition, $C_{D}$ is the parachute's drag coefficient, $S_{0}$ is the parachute's nominal area (used as the reference area for $C_{D}$ ), and $S_{p}$ is the parachute's inflated projected area. Note that the value of $\Delta p$ determined by equation (9) is the drag of the parachute, $q C_{D} S_{0}$, divided by the projected area, $S_{p}$. A simplified calculation for $\Delta p$ is

$$
\Delta p=q \quad[\text { Method 2] }
$$

The differential pressure yielded by equation (10) is equivalent to assuming that the inside of the canopy is at total pressure and the outside is at freestream static pressure (in incompressible flow).

Both methods yield approximate values of $\Delta p$ on the parachute's fabric. Method 1 is theoretically more accurate, because it accounts for the relationship between the differential pressure across the fabric and the parachute drag, but it requires knowledge of $C_{D}, S_{0}$, and $S_{p}$. Method 2 only requires knowledge of the dynamic pressure at the flight condition.

Results using the equations above are presented in table 7 for two Disk-Gap-Band (DGB) parachutes of nearly identical geometry and tested at essentially the same conditions (i.e., Mach number and dynamic pressure). These DGB parachutes were subscale (6.7 percent) models simulating the Mars Science Laboratory (MSL) descent configuration. They were tested in the NASA Langley Research Center Transonic Dynamics Tunnel as described in reference 1. Each parachute was fabricated using either PIA-C-7020D Type I or PIA-C-44378D Type I fabric. The test condition was selected because it is relevant to Mars-flight operations. A value of $k=0.7$ was assumed in the calculations. For the parachute fabricated from PIA-C-7020D Type I fabric, the contribution of fabric permeability to the total porosity was significant: $\left(1-\lambda_{g}\right) c_{e} / \lambda_{T} \approx 0.21$. Conversely, for the parachute fabricated from PIA-C-44378D Type I fabric, the contribution of fabric permeability to the total porosity was insignificant: $\left(1-\lambda_{g}\right) c_{e} / \lambda_{T}<0.005$. Both parachutes had nearly the same geometric porosity. However, the contribution of fabric permeability yielded a large difference in the total porosity, $\lambda_{T} \approx 0.107$ vs. $\lambda_{T} \approx 0.084$, for the parachutes fabricated from PIA-C-7020D Type I and PIA-C-44378D Type I fabrics, respectively. In this example the difference between the Method 1 and Method 2 calculations yielded only small differences in $c_{e}$ and $\lambda_{T}$. 
Table 7. Example total porosity calculations for two Disk-Gap-Band parachutes.

\begin{tabular}{|c|c|c|c|}
\hline \multirow{2}{*}{ Quantity } & \multirow{2}{*}{ Units } & \multicolumn{2}{|c|}{ Parachute Fabric } \\
\hline & & PIA-C-7020D Type I & PIA-C-44378D Type I \\
\hline \multirow{2}{*}{$S_{0}$} & $\mathrm{ft}^{2}$ & 17.22 & 17.44 \\
\hline & $\mathrm{m}^{2}$ & 1.600 & 1.620 \\
\hline \multirow{2}{*}{$S_{p}$} & $\mathrm{ft}^{2}$ & 9.28 & 9.40 \\
\hline & $\mathrm{m}^{2}$ & 0.862 & 0.873 \\
\hline$S_{0} / S_{p}$ & - & 1.856 & 1.856 \\
\hline$C_{D}$ & - & 0.583 & 0.626 \\
\hline$C_{D} S_{0} / S_{P}$ & - & 1.083 & 1.163 \\
\hline \multirow{2}{*}{$q$} & psf & 14.02 & 14.36 \\
\hline & $\mathrm{Pa}$ & 671.2 & 687.7 \\
\hline \multirow{2}{*}{$\Delta p[$ Method 1$]$} & psf & 15.18 & 16.70 \\
\hline & $\mathrm{Pa}$ & 726.9 & 799.7 \\
\hline \multirow{2}{*}{$\Delta p[$ Method 2] } & psf & 14.02 & 14.36 \\
\hline & $\mathrm{Pa}$ & 671.2 & 687.7 \\
\hline \multirow{2}{*}{$\mu$} & $\operatorname{slug} /(\mathrm{ft} \bullet \mathrm{s})$ & $3.733 \mathrm{E}-07$ & $3.738 \mathrm{E}-07$ \\
\hline & $\mathrm{kg} /(\mathrm{m} \cdot \mathrm{s})$ & $1.787 \mathrm{E}-05$ & $1.790 \mathrm{E}-05$ \\
\hline \multirow[b]{2}{*}{$\rho$} & $\operatorname{slug} / \mathrm{ft}^{3}$ & $1.346 \mathrm{E}-04$ & $1.365 \mathrm{E}-04$ \\
\hline & $\mathrm{kg} / \mathrm{m}^{3}$ & $6.938 \mathrm{E}-02$ & $7.037 \mathrm{E}-02$ \\
\hline \multirow{2}{*}{$\hat{R} e[$ Method 1] } & $1 / \mathrm{ft}$ & $1.713 \mathrm{E}+05$ & $1.807 \mathrm{E}+05$ \\
\hline & $1 / \mathrm{m}$ & $5.620 \mathrm{E}+05$ & $5.927 \mathrm{E}+05$ \\
\hline \multirow{2}{*}{$\hat{R} e[$ Method 2] } & $1 / \mathrm{ft}$ & $1.646 \mathrm{E}+05$ & $1.675 \mathrm{E}+05$ \\
\hline & $1 / \mathrm{m}$ & $5.400 \mathrm{E}+05$ & $5.497 \mathrm{E}+05$ \\
\hline$K_{1}$ & - & $1.588 \mathrm{E}+02$ & $1.130 \mathrm{E}+04$ \\
\hline \multirow{2}{*}{$K_{2}$} & $1 / \mathrm{ft}$ & $2.630 \mathrm{E}+06$ & $2.371 \mathrm{E}+08$ \\
\hline & $1 / \mathrm{m}$ & $8.629 \mathrm{E}+06$ & $7.780 \mathrm{E}+08$ \\
\hline$c_{e}[$ Method 1] & - & 0.02572 & 0.00038 \\
\hline$c_{e}[$ Method 2] & - & 0.02505 & 0.00035 \\
\hline$k$ & - & 0.7 & 0.7 \\
\hline$\lambda_{g}$ & - & 0.1210 & 0.1197 \\
\hline$k \lambda_{g}$ & - & 0.0847 & 0.0838 \\
\hline$\left(1-\lambda_{g}\right) c_{e}[$ Method 1] & - & 0.0226 & 0.0003 \\
\hline$\left(1-\lambda_{g}\right) c_{e}[$ Method 2] & - & 0.0220 & 0.0003 \\
\hline$\lambda_{T}[$ Method 1$]$ & - & 0.1073 & 0.0841 \\
\hline$\lambda_{T}[$ Method 2] & - & 0.1067 & 0.0841 \\
\hline$\left(1-\lambda_{g}\right) c_{e} / \lambda_{T}[$ Method 1] & - & 0.2107 & 0.0040 \\
\hline$\left(1-\lambda_{g}\right) c_{e} / \lambda_{T}[$ Method 2] & - & 0.2063 & 0.0037 \\
\hline
\end{tabular}

Notes: The test Mach numbers were 0.41 for the data shown above. The effective porosities, $c_{e}$, were calculated using the " $K_{1}, K_{2}$ model" defined by equation (6) with the values for $K_{1}$ and $K_{2}$ presented in table 6 . 
As expected, drag coefficient is affected by the total porosity. The parachute with the lower total porosity $\left(\lambda_{T} \approx 0.084\right.$, fabricated from PIA-C-44378 Type I fabric) has a higher drag coefficient, $C_{D}=0.626$, than the one with the higher total porosity $\left(\lambda_{T} \approx 0.107\right.$ fabricated from PIA-C-7020D Type I fabric), $C_{D}=0.583$.

With the calculated values of $\lambda_{T}$, and the known values of $C_{D}$ at the test condition being considered, an interpolation was constructed to determine an estimated value of $C_{D}$ at a different flight condition. Based on the data in table 7, the following linear relationships between $\lambda_{T}$ and $C_{D}$ were defined using the data for both parachutes:

$$
\begin{array}{ll}
C_{D}=C_{0, M 1}+C_{1, M 1} \lambda_{T, M 1} & \text { [Method 1] } \\
C_{D}=C_{0, M 2}+C_{1, M 2} \lambda_{T, M 2} & \text { [Method 2] }
\end{array}
$$

Note that the identities of Method 1 and Method 2 were retained in equations (11) and (12), respectively, by specifying different linear constants $\left(C_{0, M 1}, C_{1, M 1}\right)$ and $\left(C_{0, M 2}, C_{1, M 2}\right)$. Values for these constants are given in table 8 . Note that the linear relationships specified in equations (11) and (12) with the constants shown in table 8 are specific to the example's parachute/payload geometry (MSL) and Mach number (0.41).

Table 8. Values of constants in equations (11) and (12) for the example.

\begin{tabular}{|l|c|c|}
\cline { 2 - 3 } \multicolumn{1}{c|}{} & $C_{0}$ & $C_{1}$ \\
\hline Method 1 (subscript $M 1)$ & 0.782417 & -1.85371 \\
\hline Method 2 (subscript $M 2)$ & 0.786256 & -1.89989 \\
\hline
\end{tabular}

The next step is to derive equations for the determination of $C_{D}$ given the flight conditions and the parachute fabric used. Considering Method 1 first, combining equations (11), (7), (6), (8), and (9) yields

$$
C_{D}=C_{0, M 1}+C_{1, M 1}\left[k \lambda_{g}+\left(1-\lambda_{g}\right)\left(\frac{-K_{2} \mu}{2 K_{1} \sqrt{2 \rho \frac{q C_{D} S_{0}}{S_{p}}}}+\sqrt{\frac{\left(K_{2} \mu\right)^{2}}{8 K_{1}^{2} \rho \frac{q C_{D} S_{0}}{S_{p}}}+\frac{1}{2 K_{1}}}\right)\right]
$$

Similarly, for Method 2, combining equations (11), (7), (6), (8), and (10) yields

$$
C_{D}=C_{0, M 2}+C_{1, M 2}\left[k \lambda_{g}+\left(1-\lambda_{g}\right)\left(\frac{-K_{2} \mu}{2 K_{1} \sqrt{2 \rho q}}+\sqrt{\frac{\left(K_{2} \mu\right)^{2}}{8 K_{1}^{2} \rho q}+\frac{1}{2 K_{1}}}\right)\right]
$$

Several observations can be made regarding equations (13) and (14): 
1. The flight parameters needed are $q, \rho$, and $\mu$.

2. The equations are applicable to essentially the same parachute/payload geometry as that used to determine $C_{0}$ and $C_{1}$. When using Method 1, small differences in $\lambda_{g}$ and/or $S_{0} / S_{p}$ are taken into consideration. Because the values of $\lambda_{g}$ are nearly constant, the sensitivity of $C_{D}$ to the assumed value of $k$ is small (however, the value of $k$ is subject to the limitation specified in observation 3 ).

3. The value of $k$ used with these equations has to be the same used in the original determination of $\lambda_{T}(k=0.7$ in the present example).

4. The equations are applicable for parachutes using any fabric material for which $K_{1}$ and $K_{2}$ are known.

5. Equation (13) [Method 1] is implicit; that is, $C_{D}$ appears both on the right and left hand sides of the equation. Thus, equation (13) needs to be solved numerically for $C_{D}$.

6. Equation (14) [Method 2] is explicit; that is, $C_{D}$ appears only on the left hand side of the equation. Thus, with Method 2, $C_{D}$ can be calculated directly using equation (14).

The flight condition shown in table 9 is a reconstructed value of that experienced by MSL during descent on Mars at a Mach number of 0.41 . Note that this flight condition occurs in an atmosphere consisting mostly of carbon dioxide. Additional data on the MSL parachute are given in table 10 .

Table 9. Conditions experienced by MSL during descent on Mars at a Mach number of $\mathbf{0 . 4 1}$, as obtained from flight reconstruction.

\begin{tabular}{|l|c|r|}
\hline Quantity & Units & \multicolumn{1}{l|}{ Value } \\
\hline \multirow{2}{*}{$q$} & $\mathrm{psf}$ & 0.8217 \\
\cline { 2 - 3 } & $\mathrm{Pa}$ & 39.34 \\
\hline \multirow{2}{*}{$\rho$} & $\mathrm{slug} / \mathrm{ft}^{3}$ & $1.627 \mathrm{E}-05$ \\
\cline { 2 - 3 } & $\mathrm{kg} / \mathrm{m}^{3}$ & $8.384 \mathrm{E}-03$ \\
\hline \multirow{2}{*}{$\mu$} & $\mathrm{slug} /(\mathrm{ft} \bullet \mathrm{s})$ & $2.344 \mathrm{E}-07$ \\
\cline { 2 - 3 } & $\mathrm{kg} /(\mathrm{m} \bullet \mathrm{s})$ & $1.122 \mathrm{E}-05$ \\
\hline
\end{tabular}

Table 10. Additional data on the MSL parachute.

\begin{tabular}{|c|c|l|}
\hline Quantity & Value or Specification & Comment \\
\hline$\lambda_{g}$ & 0.1280 & $\begin{array}{l}\text { Actual. See reference 9. Slightly higher than that for the } \\
\text { subscale model parachutes. }\end{array}$ \\
\hline$S_{0} / S_{p}$ & 1.856 & Assumed to be the same as the subscale model parachutes. \\
\hline Fabric & PIA-C-7020D Type I & $\begin{array}{l}\text { Assumed. The actual MSL parachute was mostly } \\
\text { fabricated from PIA-C-7020B Type I and PIA-C-7020C } \\
\text { Type I fabric. However, a 1.4 oz/yd }{ }^{2} \text { polyester was used in } \\
\text { the crown area. See reference 9. }\end{array}$ \\
\hline
\end{tabular}

Applying the data in tables 9 and 10 to equations (13) and (14) yielded the estimates for $C_{D}$ shown in table 11. Because of the low-density Mars environment and operation at low dynamic 
pressures, the value of $\hat{R} e$ was very low, in turn yielding low values of $c_{e}$ and $\lambda_{T}$. The values of $C_{D}$ obtained in this example were the same for both Methods 1 and 2 for all practical purposes. The value $C_{D}=0.609$ obtained herein is close to the pre-flight estimated nominal $C_{D}$ value of 0.615 used in the flight mechanics simulations for MSL (see reference. 9). This comparison, however, needs to be considered in light of the differences in fabric materials noted in the "Comments" column of table 10 and the uncertainty bounds on the pre-flight estimated nominal value of $C_{D}$ namely \pm 12.5 percent.

\section{Table 11. Drag coefficient interpolation results for the MSL on-Mars flight condition example.}

\begin{tabular}{|l|c|r|r|}
\hline Quantity & Units & Method 1 & \multicolumn{1}{l|}{ Method 2 } \\
\hline \multirow{2}{*}{$\Delta p$} & psf & 0.9291 & 0.8217 \\
\cline { 2 - 4 } & Pa & 44.49 & 39.34 \\
\hline \multirow{2}{*}{$\hat{R} e$} & $1 / \mathrm{ft}$ & $2.346 \mathrm{E}+04$ & $2.206 \mathrm{E}+04$ \\
\cline { 2 - 4 } & $1 / \mathrm{m}$ & $7.697 \mathrm{E}+04$ & $7.238 \mathrm{E}+04$ \\
\hline$c_{e}$ & - & 0.0044 & 0.0042 \\
\hline$\lambda_{T}$ & - & 0.0935 & 0.0932 \\
\hline$C_{D}$ & - & 0.609 & 0.609 \\
\hline
\end{tabular}

\section{Concluding Remarks}

The fabric permeability data obtained served its principal purpose - to aid in the interpretation and use of parachute data. The expected relationship between total porosity and drag coefficient was confirmed. Combining the effective porosity models (derived from the fabric permeability data) with the wind tunnel test results allowed for an estimation of the drag coefficient of the example parachute system geometry (MSL) operating at the same Mach number on Mars. This estimate of the drag coefficient is close to the nominal pre-flight estimated value, giving credibility to the analysis approach presented in this technical memorandum.

A suggested topic for follow-on research is to verify the assumption that the effective porosity of parachute fabrics can be modeled as a function of unit Reynolds number, independent of the upstream pressure, $p$, at which the test is conducted, and independent of the gas used for testing. Note that the pressure- and gas-independence assumptions were made in the final set of calculations for the example; the effective porosity of the fabrics were determined in air at ambient upstream pressure, and these data were used in calculations for Mars' low-pressure carbon dioxide atmosphere. 


\section{References}

1. Zumwalt, C. H., Cruz, J. R., O'Farrell, C., and Keller, D. F., "Wind Tunnel Test of Subscale Ringsail and Disk-Gap-Band Parachutes," AIAA Paper 2016-3426, presented at the $34^{\text {th }}$ AIAA Applied Aerodynamics Conference, AIAA Aviation and Aeronautics Forum and Exposition, Washington, D. C., June 13-17, 2016.

2. Anon., Parachute Industry Association Commercial Specification ${ }^{\circledR}$, "Cloth, Parachute, Nylon-Rip Stop and Twill Weave," PIA-C-7020D, November 17, 2010.

3. Anon., Parachute Industry Association Commercial Specification ${ }^{\mathrm{TM}}$, "Cloth, Parachute, Nylon, Low-Permeability," PIA-C-44378D, May 3, 2007.

4. Anon., "Standard Test Method for Air Permeability of Textile Fabrics," ASTM International Standard Test Method D737 - 04 (Reapproved 2012), August 2012.

5. Lingard, J. and Underwood, J, "The Effect of Low Density Atmospheres on the Aerodynamic Coefficients of Parachutes," AIAA Paper 95-1556, presented at the $13^{\text {th }}$ AIAA Aerodynamic Decelerator Systems Technology Conference, Clearwater, FL, May 15-19, 1995.

6. Lingard, S., "Aerodynamics 1 (Steady)," lecture notes for the Parachute Systems Technology Short Course, U. S. Army Proving Ground, May 12-16, 2008.

7. Heinrich, H. G and Haak, E. L., "Stability and Drag of Parachutes with Varying Effective Porosity," AFFDL-TR-71-58, Air Force Flight Dynamics Laboratory, Wright-Patterson Air Force Base, Dayton, OH, February 1971.

8. Anon., "U.S. Standard Atmosphere, 1976," NOAA, NASA, and USAF, NASA-TM-X-74335, Washington, D.C., October 1976.

9. Cruz, J. R., Way, D. W., Shidner, J. D., Davis, J. L., Adams, D. S., and Kipp, D. M., "Reconstruction of the Mars Science Laboratory Parachute Performance," Journal of Spacecraft and Rockets, Vol. 51, No. 4, pp. 1185-1196, July-August 2014. 


\section{Appendix A Permeability Test Results}

Table A1. Permeability results for PIA-C-7020D Type I fabric in chronological testing order.

\begin{tabular}{|c|c|c|c|c|c|c|c|c|c|c|c|c|c|}
\hline \multirow[t]{2}{*}{ Sample } & \multirow[t]{2}{*}{ Date } & \multirow{2}{*}{$\begin{array}{l}\text { Time } \\
\text { (PST) }\end{array}$} & \multicolumn{3}{|c|}{ Atmospheric Pressure, $p$} & \multicolumn{3}{|c|}{ Temperature, $T$} & \multirow{2}{*}{$\begin{array}{c}\text { Relative } \\
\text { Humidity, } \\
R H\end{array}$} & \multicolumn{2}{|c|}{$\begin{array}{l}\text { Differential Pressure, } \\
\qquad \Delta p\end{array}$} & \multicolumn{2}{|c|}{ Permeability, $u$} \\
\hline & & & (in. $\mathrm{Hg}$ ) & (psf) & $(\mathrm{Pa})$ & $\left({ }^{\circ} \mathrm{F}\right)$ & $\left({ }^{\circ} \mathrm{R}\right)$ & $(\mathrm{K})$ & & (psf) & $(\mathrm{Pa})$ & $\left(\mathrm{ft}^{3} / \mathrm{ft}^{2} / \mathrm{min}\right)$ & $\left(\mathrm{cm}^{3} / \mathrm{cm}^{2} / \mathrm{s}\right)$ \\
\hline 1 & $1 / 21 / 16$ & $11: 13$ & 28.00 & 1980 & 94819 & 71.8 & 531.5 & 295.3 & 34.2 & 0.146 & 7.0 & 9.06 & 4.60 \\
\hline 1 & $1 / 21 / 16$ & $11: 17$ & 28.00 & 1980 & 94819 & 72.1 & 531.8 & 295.4 & 34.2 & 0.251 & 12.0 & 14.76 & 7.50 \\
\hline 1 & $1 / 21 / 16$ & $11: 23$ & 28.00 & 1980 & 94819 & 72.3 & 532.0 & 295.5 & 34.2 & 0.501 & 24.0 & 27.17 & 13.80 \\
\hline 1 & $1 / 21 / 16$ & $11: 28$ & 27.99 & 1980 & 94785 & 72.4 & 532.1 & 295.6 & 35.3 & 0.752 & 36.0 & 37.80 & 19.20 \\
\hline 1 & $1 / 21 / 16$ & $11: 33$ & 27.99 & 1980 & 94785 & 72.7 & 532.4 & 295.8 & 33.7 & 1.003 & 48.0 & 47.44 & 24.10 \\
\hline 1 & $1 / 21 / 16$ & $11: 38$ & 27.99 & 1980 & 94785 & 72.8 & 532.5 & 295.8 & 33.7 & 2.047 & 98.0 & 81.50 & 41.40 \\
\hline 1 & $1 / 21 / 16$ & $11: 42$ & 27.99 & 1980 & 94785 & 73.0 & 532.7 & 295.9 & 33.7 & 3.008 & 144.0 & 107.87 & 54.80 \\
\hline 1 & $1 / 21 / 16$ & $11: 47$ & 27.99 & 1980 & 94785 & 73.1 & 532.8 & 296.0 & 33.1 & 5.994 & 287.0 & 174.41 & 88.60 \\
\hline 1 & $1 / 21 / 16$ & $11: 51$ & 27.99 & 1980 & 94785 & 73.2 & 532.9 & 296.0 & 33.1 & 12.009 & 575.0 & 275.59 & 140.00 \\
\hline 1 & $1 / 21 / 16$ & $11: 56$ & 27.98 & 1979 & 94751 & 73.4 & 533.1 & 296.2 & 33.3 & 25.000 & 1197.0 & 444.88 & 226.00 \\
\hline 1 & $1 / 21 / 16$ & $12: 00$ & 27.97 & 1978 & 94717 & 73.5 & 533.2 & 296.2 & 33.1 & 0.146 & 7.0 & 8.94 & 4.54 \\
\hline 2 & $1 / 21 / 16$ & $12: 02$ & 27.97 & 1978 & 94717 & 73.6 & 533.3 & 296.3 & 33.2 & 0.146 & 7.0 & 7.95 & 4.04 \\
\hline 2 & $1 / 21 / 16$ & $12: 06$ & 27.97 & 1978 & 94717 & 73.6 & 533.3 & 296.3 & 33.2 & 1.003 & 48.0 & 43.31 & 22.00 \\
\hline 2 & $1 / 21 / 16$ & $12: 10$ & 27.97 & 1978 & 94717 & 73.7 & 533.4 & 296.3 & 33.2 & 3.008 & 144.0 & 98.82 & 50.20 \\
\hline 2 & $1 / 21 / 16$ & $12: 14$ & 27.97 & 1978 & 94717 & 73.9 & 533.6 & 296.4 & 33.2 & 0.251 & 12.0 & 13.13 & 6.67 \\
\hline 2 & $1 / 21 / 16$ & $12: 19$ & 27.96 & 1978 & 94683 & 73.9 & 533.6 & 296.4 & 33.2 & 0.501 & 24.0 & 24.61 & 12.50 \\
\hline 2 & $1 / 21 / 16$ & $12: 23$ & 27.96 & 1978 & 94683 & 73.9 & 533.6 & 296.4 & 33.0 & 5.994 & 287.0 & 160.83 & 81.70 \\
\hline 2 & $1 / 21 / 16$ & $12: 26$ & 27.95 & 1977 & 94650 & 74.0 & 533.7 & 296.5 & 33.2 & 25.000 & 1197.0 & 411.42 & 209.00 \\
\hline 2 & $1 / 21 / 16$ & $12: 30$ & 27.95 & 1977 & 94650 & 74.1 & 533.8 & 296.5 & 32.9 & 12.009 & 575.0 & 259.84 & 132.00 \\
\hline 2 & $1 / 21 / 16$ & $12: 34$ & 27.95 & 1977 & 94650 & 74.1 & 533.8 & 296.5 & 32.6 & 0.752 & 36.0 & 35.43 & 18.00 \\
\hline 2 & $1 / 21 / 16$ & $12: 38$ & 27.95 & 1977 & 94650 & 74.1 & 533.8 & 296.5 & 32.5 & 2.047 & 98.0 & 76.77 & 39.00 \\
\hline 2 & $1 / 21 / 16$ & $12: 42$ & 27.95 & 1977 & 94650 & 74.3 & 534.0 & 296.7 & 32.6 & 0.146 & 7.0 & 8.11 & 4.12 \\
\hline
\end{tabular}


Table A1. Permeability results for PIA-C-7020D Type I fabric in chronological testing order. Concluded.

\begin{tabular}{|c|c|c|c|c|c|c|c|c|c|c|c|c|c|}
\hline \multirow{2}{*}{ Sample } & \multirow{2}{*}{ Date } & \multirow{2}{*}{$\begin{array}{l}\text { Time } \\
\text { (PST) }\end{array}$} & \multicolumn{3}{|c|}{ Atmospheric Pressure, $p$} & \multicolumn{3}{|c|}{ Temperature, $T$} & \multirow{2}{*}{$\begin{array}{c}\text { Relative } \\
\text { Humidity, } \\
R H \\
(\%)\end{array}$} & \multicolumn{2}{|c|}{$\begin{array}{l}\text { Differential Pressure, } \\
\qquad \Delta p\end{array}$} & \multicolumn{2}{|c|}{ Permeability, $u$} \\
\hline & & & (in. $\mathrm{Hg}$ ) & (psf) & $(\mathrm{Pa})$ & $\left({ }^{\circ} \mathrm{F}\right)$ & $\left({ }^{\circ} \mathrm{R}\right)$ & $(\mathrm{K})$ & & (psf) & $(\mathrm{Pa})$ & $\left(\mathrm{ft}^{3} / \mathrm{ft}^{2} / \min \right)$ & $\left(\mathrm{cm}^{3} / \mathrm{cm}^{2} / \mathrm{s}\right)$ \\
\hline 3 & $1 / 21 / 16$ & $12: 47$ & 27.95 & 1977 & 94650 & 74.3 & 534.0 & 296.7 & 32.1 & 0.146 & 7.0 & 8.50 & 4.32 \\
\hline 3 & $1 / 21 / 16$ & $12: 52$ & 27.94 & 1976 & 94616 & 74.1 & 533.8 & 296.5 & 32.1 & 0.251 & 12.0 & 14.09 & 7.16 \\
\hline 3 & $1 / 21 / 16$ & $12: 56$ & 27.94 & 1976 & 94616 & 74.1 & 533.8 & 296.5 & 32.2 & 2.047 & 98.0 & 81.50 & 41.40 \\
\hline 3 & $1 / 21 / 16$ & $13: 01$ & 27.94 & 1976 & 94616 & 74.2 & 533.9 & 296.6 & 32.1 & 12.009 & 575.0 & 277.56 & 141.00 \\
\hline 3 & $1 / 21 / 16$ & $13: 05$ & 27.94 & 1976 & 94616 & 74.2 & 533.9 & 296.6 & 32.1 & 5.994 & 287.0 & 175.39 & 89.10 \\
\hline 3 & $1 / 21 / 16$ & $13: 08$ & 27.94 & 1976 & 94616 & 74.2 & 533.9 & 296.6 & 32.1 & 0.752 & 36.0 & 37.99 & 19.30 \\
\hline 3 & $1 / 21 / 16$ & $13: 13$ & 27.93 & 1975 & 94582 & 74.3 & 534.0 & 296.7 & 32.1 & 25.000 & 1197.0 & 452.76 & 230.00 \\
\hline 3 & $1 / 21 / 16$ & $13: 16$ & 27.93 & 1975 & 94582 & 74.3 & 534.0 & 296.7 & 31.9 & 1.003 & 48.0 & 48.23 & 24.50 \\
\hline 3 & $1 / 21 / 16$ & $13: 20$ & 27.93 & 1975 & 94582 & 74.4 & 534.1 & 296.7 & 31.6 & 0.501 & 24.0 & 27.17 & 13.80 \\
\hline 3 & $1 / 21 / 16$ & $13: 24$ & 27.93 & 1975 & 94582 & 74.4 & 534.1 & 296.7 & 31.2 & 3.008 & 144.0 & 109.45 & 55.60 \\
\hline 3 & $1 / 21 / 16$ & $13: 27$ & 27.93 & 1975 & 94582 & 74.4 & 534.1 & 296.7 & 30.9 & 0.146 & 7.0 & 8.48 & 4.31 \\
\hline 4 & $1 / 21 / 16$ & $13: 30$ & 27.93 & 1975 & 94582 & 74.4 & 534.1 & 296.7 & 30.9 & 0.146 & 7.0 & 8.01 & 4.07 \\
\hline 4 & $1 / 21 / 16$ & $13: 34$ & 27.92 & 1975 & 94548 & 74.5 & 534.2 & 296.8 & 30.9 & 3.008 & 144.0 & 103.15 & 52.40 \\
\hline 4 & $1 / 21 / 16$ & $13: 37$ & 27.92 & 1975 & 94548 & 74.6 & 534.3 & 296.8 & 32.6 & 1.003 & 48.0 & 45.28 & 23.00 \\
\hline 4 & $1 / 21 / 16$ & $13: 41$ & 27.92 & 1975 & 94548 & 74.6 & 534.3 & 296.8 & 30.9 & 25.000 & 1197.0 & 427.17 & 217.00 \\
\hline 4 & $1 / 21 / 16$ & $13: 45$ & 27.92 & 1975 & 94548 & 74.6 & 534.3 & 296.8 & 30.9 & 2.047 & 98.0 & 79.13 & 40.20 \\
\hline 4 & $1 / 21 / 16$ & $13: 49$ & 27.92 & 1975 & 94548 & 74.7 & 534.4 & 296.9 & 30.3 & 0.251 & 12.0 & 13.52 & 6.87 \\
\hline 4 & $1 / 21 / 16$ & $13: 53$ & 27.92 & 1975 & 94548 & 74.7 & 534.4 & 296.9 & 29.8 & 5.994 & 287.0 & 168.70 & 85.70 \\
\hline 4 & $1 / 21 / 16$ & $13: 57$ & 27.92 & 1975 & 94548 & 74.9 & 534.6 & 297.0 & 29.8 & 0.752 & 36.0 & 36.42 & 18.50 \\
\hline 4 & $1 / 21 / 16$ & $14: 01$ & 27.90 & 1973 & 94480 & 74.9 & 534.6 & 297.0 & 29.8 & 0.501 & 24.0 & 25.79 & 13.10 \\
\hline 4 & $1 / 21 / 16$ & $14: 05$ & 27.91 & 1974 & 94514 & 75.0 & 534.7 & 297.0 & 29.8 & 12.009 & 575.0 & 267.72 & 136.00 \\
\hline 4 & $1 / 21 / 16$ & $14: 08$ & 27.91 & 1974 & 94514 & 74.9 & 534.6 & 297.0 & 29.8 & 0.146 & 7.0 & 8.09 & 4.11 \\
\hline 5 & $1 / 21 / 16$ & $14: 10$ & 27.91 & 1974 & 94514 & 74.8 & 534.5 & 296.9 & 29.8 & 0.146 & 7.0 & 9.19 & 4.67 \\
\hline 5 & $1 / 21 / 16$ & $14: 14$ & 27.91 & 1974 & 94514 & 74.9 & 534.6 & 297.0 & 29.8 & 0.251 & 12.0 & 15.55 & 7.90 \\
\hline 5 & $1 / 21 / 16$ & $14: 19$ & 27.91 & 1974 & 94514 & 75.0 & 534.7 & 297.0 & 29.3 & 0.501 & 24.0 & 29.13 & 14.80 \\
\hline 5 & $1 / 21 / 16$ & $14: 22$ & 27.91 & 1974 & 94514 & 75.2 & 534.9 & 297.2 & 29.2 & 0.752 & 36.0 & 40.94 & 20.80 \\
\hline 5 & $1 / 21 / 16$ & $14: 25$ & 27.92 & 1975 & 94548 & 73.6 & 533.3 & 296.3 & 28.5 & 1.003 & 48.0 & 51.77 & 26.30 \\
\hline 5 & $1 / 21 / 16$ & $14: 28$ & 27.91 & 1974 & 94514 & 74.6 & 534.3 & 296.8 & 29.0 & 2.047 & 98.0 & 88.98 & 45.20 \\
\hline 5 & $1 / 21 / 16$ & $14: 33$ & 27.91 & 1974 & 94514 & 74.8 & 534.5 & 296.9 & 28.6 & 3.008 & 144.0 & 117.52 & 59.70 \\
\hline 5 & $1 / 21 / 16$ & $14: 37$ & 27.91 & 1974 & 94514 & 74.9 & 534.6 & 297.0 & 28.6 & 5.994 & 287.0 & 190.16 & 96.60 \\
\hline 5 & $1 / 21 / 16$ & $14: 40$ & 27.91 & 1974 & 94514 & 74.9 & 534.6 & 297.0 & 28.1 & 12.009 & 575.0 & 301.18 & 153.00 \\
\hline 5 & $1 / 21 / 16$ & $14: 44$ & 27.91 & 1974 & 94514 & 75.2 & 534.9 & 297.2 & 28.1 & 25.000 & 1197.0 & 486.22 & 247.00 \\
\hline 5 & $1 / 21 / 16$ & $14: 48$ & 27.91 & 1974 & 94514 & 74.9 & 534.6 & 297.0 & 28.6 & 0.146 & 7.0 & 9.41 & 4.78 \\
\hline
\end{tabular}


Table A2. Permeability results for PIA-C-44378D Type I fabric in chronological testing order.

\begin{tabular}{|c|c|c|c|c|c|c|c|c|c|c|c|c|c|}
\hline \multirow{2}{*}{ Sample } & \multirow{2}{*}{ Date } & \multirow{2}{*}{$\begin{array}{l}\text { Time } \\
(\mathrm{PST})\end{array}$} & \multicolumn{3}{|c|}{ Atmospheric Pressure, $p$} & \multicolumn{3}{|c|}{ Temperature, $T$} & \multirow{2}{*}{$\begin{array}{c}\text { Relative } \\
\text { Humidity, } \\
R H \\
(\%)\end{array}$} & \multicolumn{2}{|c|}{$\begin{array}{l}\text { Differential Pressure, } \\
\qquad \Delta p\end{array}$} & \multicolumn{2}{|c|}{ Permeability, $u$} \\
\hline & & & (in. $\mathrm{Hg}$ ) & (psf) & $(\mathrm{Pa})$ & $\left({ }^{\circ} \mathrm{F}\right)$ & $\left({ }^{\circ} \mathrm{R}\right)$ & $(\mathrm{K})$ & & (psf) & $(\mathrm{Pa})$ & $\left(\mathrm{ft}^{3} / \mathrm{ft}^{2} / \min \right)$ & $\left(\mathrm{cm}^{3} / \mathrm{cm}^{2} / \mathrm{s}\right)$ \\
\hline 1 & $1 / 22 / 16$ & $6: 49$ & 27.87 & 1971 & 94379 & 72.4 & 532.1 & 295.6 & 26.1 & 0.146 & 7.0 & 0.1211 & 0.0615 \\
\hline 1 & $1 / 22 / 16$ & $6: 53$ & 27.87 & 1971 & 94379 & 72.6 & 532.3 & 295.7 & 26.1 & 0.251 & 12.0 & 0.1894 & 0.0962 \\
\hline 1 & $1 / 22 / 16$ & $6: 57$ & 27.87 & 1971 & 94379 & 72.6 & 532.3 & 295.7 & 25.2 & 0.501 & 24.0 & 0.3445 & 0.1750 \\
\hline 1 & $1 / 22 / 16$ & $7: 01$ & 27.87 & 1971 & 94379 & 72.1 & 531.8 & 295.4 & 25.8 & 0.752 & 36.0 & 0.5157 & 0.2620 \\
\hline 1 & $1 / 22 / 16$ & $7: 05$ & 27.87 & 1971 & 94379 & 71.5 & 531.2 & 295.1 & 26.0 & 1.003 & 48.0 & 0.6811 & 0.3460 \\
\hline 1 & $1 / 22 / 16$ & $7: 09$ & 27.87 & 1971 & 94379 & 71.1 & 530.8 & 294.9 & 26.0 & 2.047 & 98.0 & 1.4016 & 0.7120 \\
\hline 1 & $1 / 22 / 16$ & $7: 13$ & 27.87 & 1971 & 94379 & 70.5 & 530.2 & 294.5 & 26.6 & 3.008 & 144.0 & 2.0669 & 1.0500 \\
\hline 1 & $1 / 22 / 16$ & $7: 18$ & 27.87 & 1971 & 94379 & 70.3 & 530.0 & 294.4 & 27.2 & 5.994 & 287.0 & 3.9764 & 2.0200 \\
\hline 1 & $1 / 22 / 16$ & $7: 22$ & 27.87 & 1971 & 94379 & 70.0 & 529.7 & 294.3 & 27.2 & 12.009 & 575.0 & 7.9528 & 4.0400 \\
\hline 1 & $1 / 22 / 16$ & $7: 26$ & 27.87 & 1971 & 94379 & 69.7 & 529.4 & 294.1 & 27.2 & 25.000 & 1197.0 & 16.2205 & 8.2400 \\
\hline 1 & $1 / 22 / 16$ & $7: 30$ & 27.87 & 1971 & 94379 & 69.5 & 529.2 & 294.0 & 27.1 & 0.146 & 7.0 & 0.1197 & 0.0608 \\
\hline 2 & $1 / 22 / 16$ & $12: 42$ & 27.79 & 1965 & 94108 & 72.4 & 532.1 & 295.6 & 28.5 & 0.146 & 7.0 & 0.1350 & 0.0686 \\
\hline 2 & $1 / 22 / 16$ & $12: 46$ & 27.79 & 1965 & 94108 & 72.5 & 532.2 & 295.7 & 28.5 & 1.003 & 48.0 & 0.7638 & 0.3880 \\
\hline 2 & $1 / 22 / 16$ & $12: 50$ & 27.79 & 1965 & 94108 & 72.6 & 532.3 & 295.7 & 28.5 & 3.008 & 144.0 & 2.3425 & 1.1900 \\
\hline 2 & $1 / 22 / 16$ & $12: 54$ & 27.79 & 1965 & 94108 & 72.6 & 532.3 & 295.7 & 28.3 & 0.251 & 12.0 & 0.2067 & 0.1050 \\
\hline 2 & $1 / 22 / 16$ & $12: 58$ & 27.79 & 1965 & 94108 & 72.5 & 532.2 & 295.7 & 27.9 & 0.501 & 24.0 & 0.3858 & 0.1960 \\
\hline 2 & $1 / 22 / 16$ & $13: 03$ & 27.79 & 1965 & 94108 & 72.6 & 532.3 & 295.7 & 28.5 & 5.994 & 287.0 & 4.5669 & 2.3200 \\
\hline 2 & $1 / 22 / 16$ & $13: 07$ & 27.78 & 1965 & 94074 & 72.6 & 532.3 & 295.7 & 28.5 & 25.000 & 1197.0 & 18.1102 & 9.2000 \\
\hline 2 & $1 / 22 / 16$ & $13: 13$ & 27.78 & 1965 & 94074 & 72.6 & 532.3 & 295.7 & 28.5 & 12.009 & 575.0 & 9.1535 & 4.6500 \\
\hline 2 & $1 / 22 / 16$ & $13: 18$ & 27.78 & 1965 & 94074 & 72.6 & 532.3 & 295.7 & 28.5 & 0.752 & 36.0 & 0.5846 & 0.2970 \\
\hline 2 & $1 / 22 / 16$ & $13: 22$ & 27.78 & 1965 & 94074 & 72.6 & 532.3 & 295.7 & 28.5 & 2.047 & 98.0 & 1.5965 & 0.8110 \\
\hline 2 & $1 / 22 / 16$ & $13: 26$ & 27.78 & 1965 & 94074 & 72.6 & 532.3 & 295.7 & 28.5 & 0.146 & 7.0 & 0.1307 & 0.0664 \\
\hline
\end{tabular}


Table A2. Permeability results for PIA-C-44378D Type I fabric in chronological testing order. Concluded.

\begin{tabular}{|c|c|c|c|c|c|c|c|c|c|c|c|c|c|}
\hline \multirow{2}{*}{ Sample } & \multirow{2}{*}{ Date } & \multirow{2}{*}{$\begin{array}{l}\text { Time } \\
\text { (PST) }\end{array}$} & \multicolumn{3}{|c|}{ Atmospheric Pressure, $p$} & \multicolumn{3}{|c|}{ Temperature, $T$} & \multirow{2}{*}{$\begin{array}{c}\text { Relative } \\
\text { Humidity, } \\
R H \\
(\%)\end{array}$} & \multicolumn{2}{|c|}{$\begin{array}{c}\text { Differential Pressure, } \\
\qquad \Delta p\end{array}$} & \multicolumn{2}{|c|}{ Permeability, $u$} \\
\hline & & & (in. $\mathrm{Hg}$ ) & (psf) & $(\mathrm{Pa})$ & $\left({ }^{\circ} \mathrm{F}\right)$ & $\left({ }^{\circ} \mathrm{R}\right)$ & $(\mathrm{K})$ & & (psf) & $(\mathrm{Pa})$ & $\left(\mathrm{ft}^{3} / \mathrm{ft}^{2} / \mathrm{min}\right)$ & $\left(\mathrm{cm}^{3} / \mathrm{cm}^{2} / \mathrm{s}\right)$ \\
\hline 3 & $1 / 22 / 16$ & $13: 27$ & 27.78 & 1965 & 94074 & 72.6 & 532.3 & 295.7 & 28.5 & 0.146 & 7.0 & 0.1106 & 0.0562 \\
\hline 3 & $1 / 22 / 16$ & $13: 32$ & 27.77 & 1964 & 94040 & 72.7 & 532.4 & 295.8 & 28.5 & 0.251 & 12.0 & 0.1752 & 0.0890 \\
\hline 3 & $1 / 22 / 16$ & $13: 37$ & 27.77 & 1964 & 94040 & 72.7 & 532.4 & 295.8 & 28.5 & 2.047 & 98.0 & 1.2992 & 0.6600 \\
\hline 3 & $1 / 22 / 16$ & $13: 40$ & 27.77 & 1964 & 94040 & 72.8 & 532.5 & 295.8 & 28.5 & 12.009 & 575.0 & 7.3819 & 3.7500 \\
\hline 3 & $1 / 22 / 16$ & $13: 43$ & 27.77 & 1964 & 94040 & 72.7 & 532.4 & 295.8 & 28.5 & 5.994 & 287.0 & 3.7992 & 1.9300 \\
\hline 3 & $1 / 22 / 16$ & $13: 47$ & 27.77 & 1964 & 94040 & 72.8 & 532.5 & 295.8 & 28.5 & 0.752 & 36.0 & 0.4764 & 0.2420 \\
\hline 3 & $1 / 22 / 16$ & $13: 51$ & 27.76 & 1963 & 94006 & 72.8 & 532.5 & 295.8 & 28.2 & 25.000 & 1197.0 & 14.8425 & 7.5400 \\
\hline 3 & $1 / 22 / 16$ & $13: 55$ & 27.76 & 1963 & 94006 & 72.8 & 532.5 & 295.8 & 27.9 & 1.003 & 48.0 & 0.6457 & 0.3280 \\
\hline 3 & $1 / 22 / 16$ & $13: 59$ & 27.76 & 1963 & 94006 & 72.8 & 532.5 & 295.8 & 27.9 & 0.501 & 24.0 & 0.3406 & 0.1730 \\
\hline 3 & $1 / 22 / 16$ & $14: 03$ & 27.77 & 1964 & 94040 & 72.9 & 532.6 & 295.9 & 27.6 & 3.008 & 144.0 & 1.9626 & 0.9970 \\
\hline 3 & $1 / 22 / 16$ & $14: 07$ & 27.76 & 1963 & 94006 & 72.8 & 532.5 & 295.8 & 27.3 & 0.146 & 7.0 & 0.1128 & 0.0573 \\
\hline 4 & $1 / 25 / 16$ & $5: 21$ & 27.81 & 1967 & 94175 & 70.8 & 530.5 & 294.7 & 24.2 & 0.146 & 7.0 & 0.1079 & 0.0548 \\
\hline 4 & $1 / 25 / 16$ & $5: 25$ & 27.81 & 1967 & 94175 & 70.8 & 530.5 & 294.7 & 24.4 & 3.008 & 144.0 & 1.7697 & 0.8990 \\
\hline 4 & $1 / 25 / 16$ & 5:29 & 27.82 & 1968 & 94209 & 70.2 & 529.9 & 294.4 & 24.8 & 1.003 & 48.0 & 0.5866 & 0.2980 \\
\hline 4 & $1 / 25 / 16$ & $5: 33$ & 27.82 & 1968 & 94209 & 70.0 & 529.7 & 294.3 & 24.8 & 25.000 & 1197.0 & 14.2126 & 7.2200 \\
\hline 4 & $1 / 25 / 16$ & $5: 37$ & 27.82 & 1968 & 94209 & 69.9 & 529.6 & 294.2 & 24.8 & 2.047 & 98.0 & 1.2343 & 0.6270 \\
\hline 4 & $1 / 25 / 16$ & $5: 40$ & 27.82 & 1968 & 94209 & 69.5 & 529.2 & 294.0 & 24.8 & 0.251 & 12.0 & 0.1683 & 0.0855 \\
\hline 4 & $1 / 25 / 16$ & $5: 44$ & 27.82 & 1968 & 94209 & 69.5 & 529.2 & 294.0 & 24.8 & 5.994 & 287.0 & 3.5827 & 1.8200 \\
\hline 4 & $1 / 25 / 16$ & $5: 48$ & 27.82 & 1968 & 94209 & 69.4 & 529.1 & 293.9 & 24.8 & 0.752 & 36.0 & 0.4508 & 0.2290 \\
\hline 4 & $1 / 25 / 16$ & $5: 52$ & 27.82 & 1968 & 94209 & 69.2 & 528.9 & 293.8 & 24.8 & 0.501 & 24.0 & 0.3209 & 0.1630 \\
\hline 4 & $1 / 25 / 16$ & $5: 56$ & 27.82 & 1968 & 94209 & 69.0 & 528.7 & 293.7 & 24.5 & 12.009 & 575.0 & 7.1260 & 3.6200 \\
\hline 4 & $1 / 25 / 16$ & 6:00 & 27.82 & 1968 & 94209 & 68.7 & 528.4 & 293.5 & 23.6 & 0.146 & 7.0 & 0.1063 & 0.0540 \\
\hline 5 & $1 / 25 / 16$ & $6: 01$ & 27.82 & 1968 & 94209 & 68.7 & 528.4 & 293.5 & 24.7 & 0.146 & 7.0 & 0.1033 & 0.0525 \\
\hline 5 & $1 / 25 / 16$ & $6: 04$ & 27.82 & 1968 & 94209 & 68.6 & 528.3 & 293.5 & 24.7 & 0.251 & 12.0 & 0.1618 & 0.0822 \\
\hline 5 & $1 / 25 / 16$ & $6: 08$ & 27.83 & 1968 & 94243 & 68.4 & 528.1 & 293.4 & 24.7 & 0.501 & 24.0 & 0.2972 & 0.1510 \\
\hline 5 & $1 / 25 / 16$ & $6: 12$ & 27.83 & 1968 & 94243 & 68.0 & 527.7 & 293.2 & 24.7 & 0.752 & 36.0 & 0.4350 & 0.2210 \\
\hline 5 & $1 / 25 / 16$ & $6: 16$ & 27.83 & 1968 & 94243 & 67.7 & 527.4 & 293.0 & 24.7 & 1.003 & 48.0 & 0.5787 & 0.2940 \\
\hline 5 & $1 / 25 / 16$ & $6: 20$ & 27.83 & 1968 & 94243 & 67.5 & 527.2 & 292.9 & 25.3 & 2.047 & 98.0 & 1.1890 & 0.6040 \\
\hline 5 & $1 / 25 / 16$ & $6: 24$ & 27.83 & 1968 & 94243 & 67.4 & 527.1 & 292.8 & 25.3 & 3.008 & 144.0 & 1.7579 & 0.8930 \\
\hline 5 & $1 / 25 / 16$ & $6: 28$ & 27.83 & 1968 & 94243 & 67.2 & 526.9 & 292.7 & 25.7 & 5.994 & 287.0 & 3.5039 & 1.7800 \\
\hline 5 & $1 / 25 / 16$ & $6: 32$ & 27.83 & 1968 & 94243 & 68.1 & 527.8 & 293.2 & 24.7 & 12.009 & 575.0 & 6.9882 & 3.5500 \\
\hline 5 & $1 / 25 / 16$ & $6: 36$ & 27.82 & 1968 & 94209 & 69.7 & 529.4 & 294.1 & 24.5 & 25.000 & 1197.0 & 14.4488 & 7.3400 \\
\hline 5 & $1 / 25 / 16$ & $6: 40$ & 27.82 & 1968 & 94209 & 70.5 & 530.2 & 294.5 & 23.6 & 0.146 & 7.0 & 0.1065 & 0.0541 \\
\hline
\end{tabular}




\section{Appendix B Replicate Permeability Test Results}

Replicate permeability tests were conducted to evaluate the test-to-test contribution to the variation in the permeability results. Sample 3 of the PIA-C-7020D Type I fabric was retested three times (replicates 1-3), using its corresponding test sequence as shown in table 2. Samples 3 and 4 of the PIA-C-44378D Type I fabric were retested three times each (replicates 1-3), using their corresponding test sequences as shown in table 2 . The samples were reset in the instrument between replicate tests. The results of the original tests (symbols), and the replicate tests (interpolated lines) are shown in Figure B1 and Figure B2. The replicate tests' data are presented numerically in Table B1 and Table B2. From these figures and tables it was observed that the test-to-test contribution to the variation observed in the original results was relatively small as compared to the sample-to-sample variation.

For Sample 3, most replicate results (blue dashed lines) using the PIA-C-7020D Type I and PIA-C-44378D Type I fabrics were within 4.8 percent of the values obtained in the original tests (symbol $\Delta$ ). (All comparisons in this paragraph used the average of the results for a given

differential pressure. Percent comparisons used the original results as the baseline.) The two exceptions to this were the results for the two lowest differential pressure values, $0.146 \mathrm{psf}(7 \mathrm{~Pa})$ and $0.251 \mathrm{psf}(12 \mathrm{~Pa})$ using the PIA-C-7020D Type I fabric; the difference between the original and replicate results were 8.8 and 6.2 percent, respectively. For Sample 4 using the PIA-C-44378D Type I fabric, replicate results (green dotted lines) were within 6.7 percent of those obtained in the original tests (symbol $\bullet$ ). 


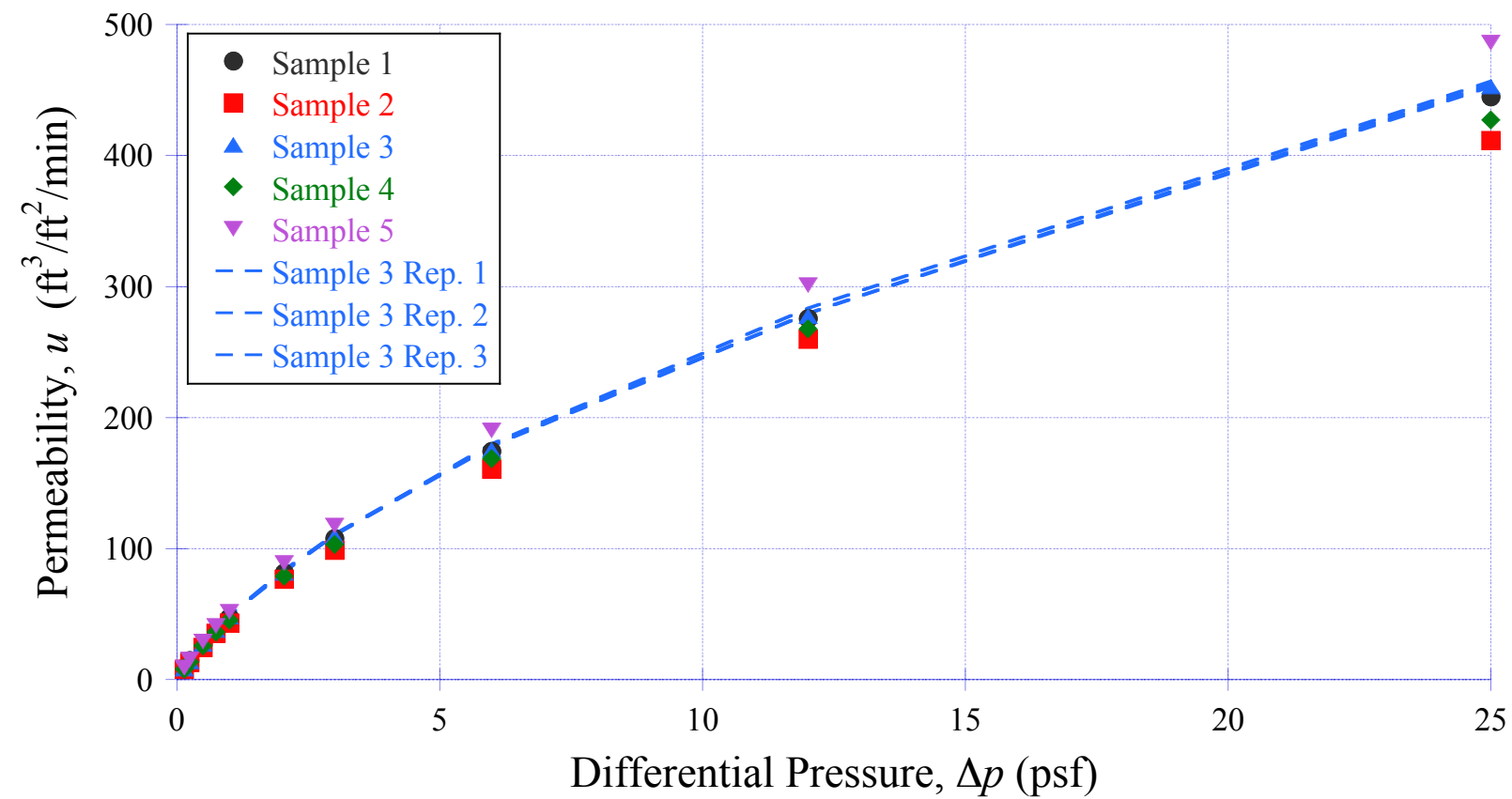

(a) Full differential pressure range: $0.146-25$ psf (7-1197 Pa).

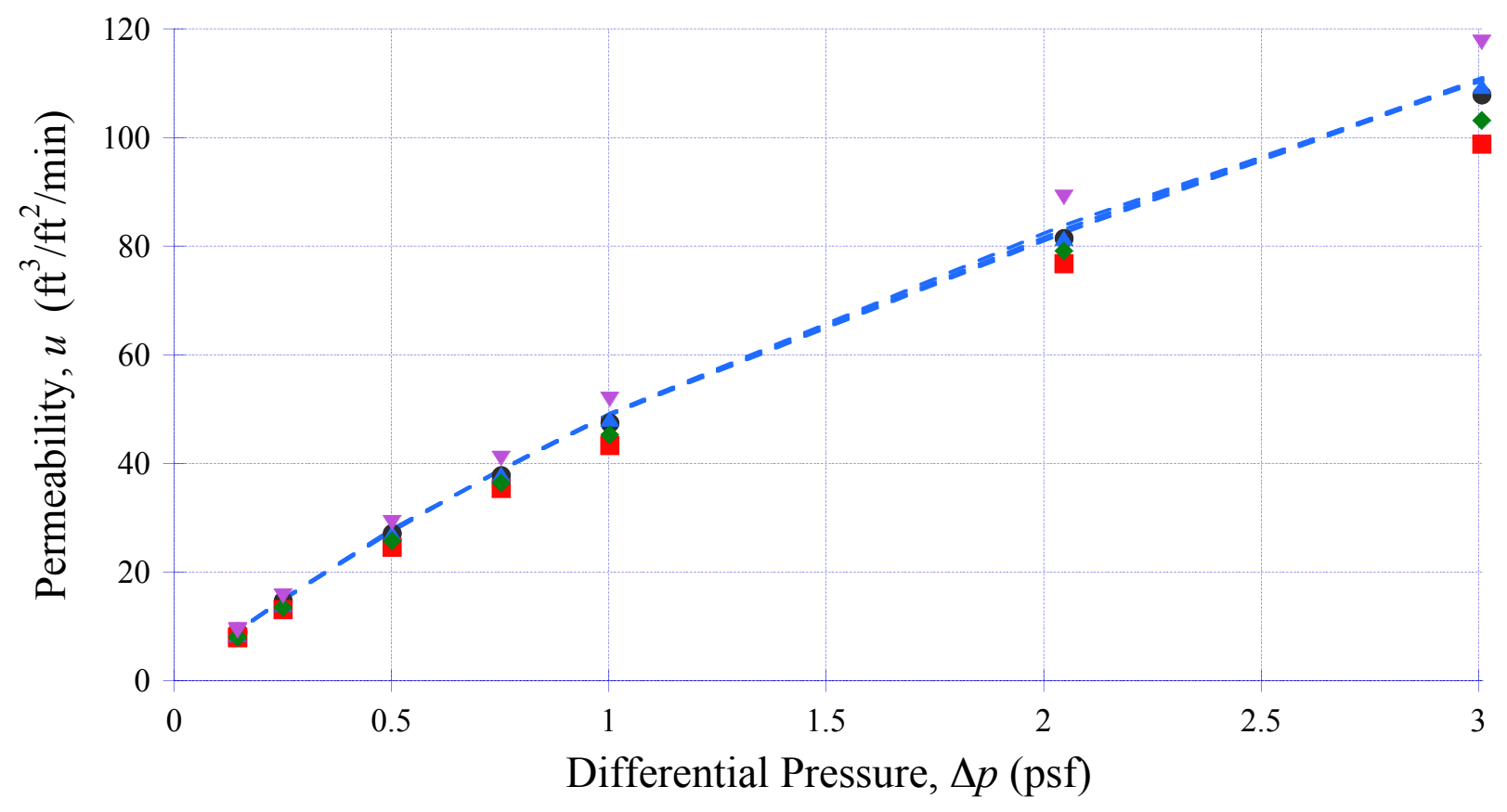

(b) Close up of the lower differential pressure range: $0.146-3$ psf (7-143.6 Pa).

Figure B1. Original and replicate permeability results for PIA-C-7020D Type I fabric. 


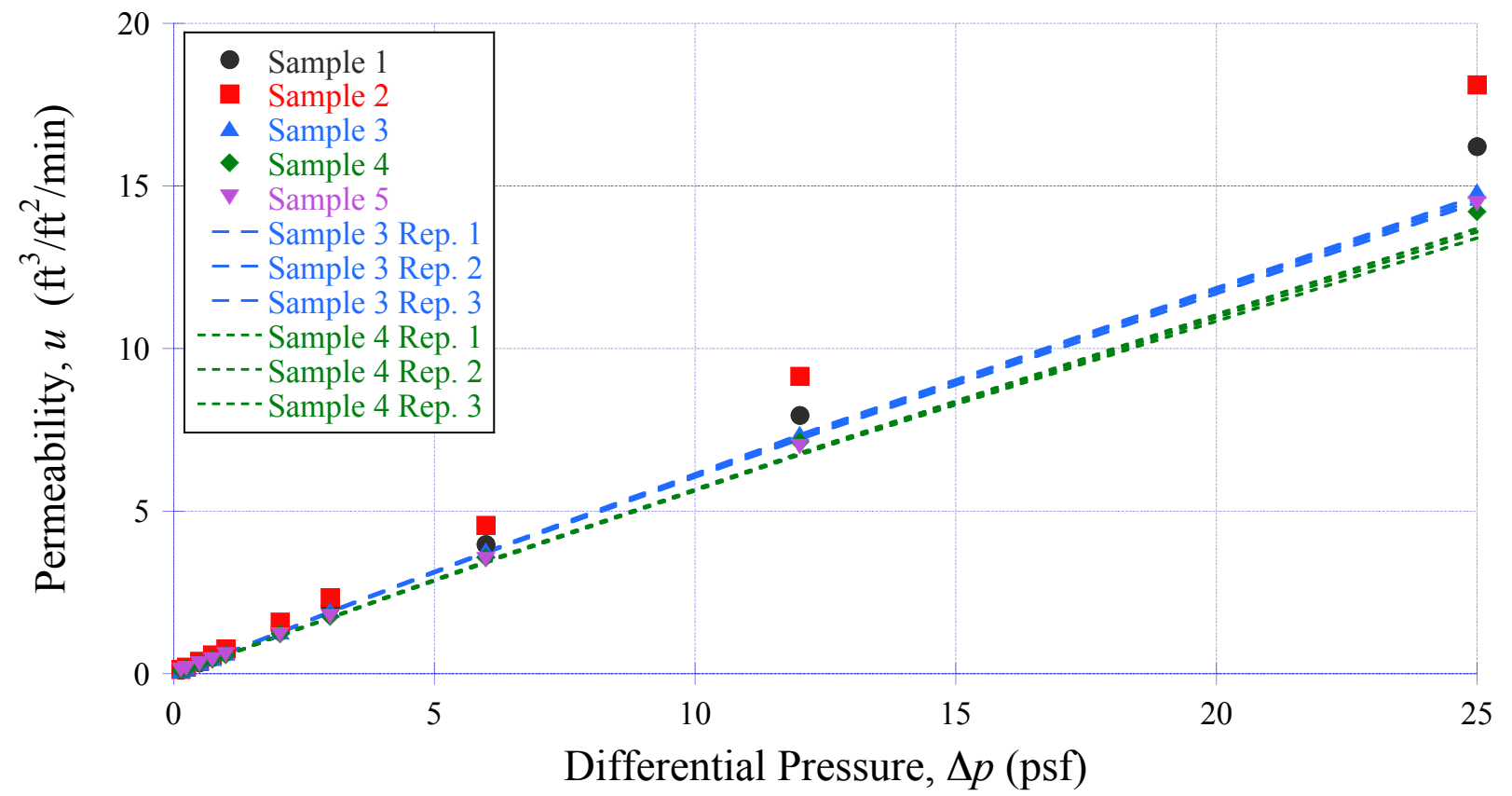

(a) Full differential pressure range: 0.146 to $25 \mathrm{psf}$ (7 to $1197 \mathrm{~Pa}$ ).

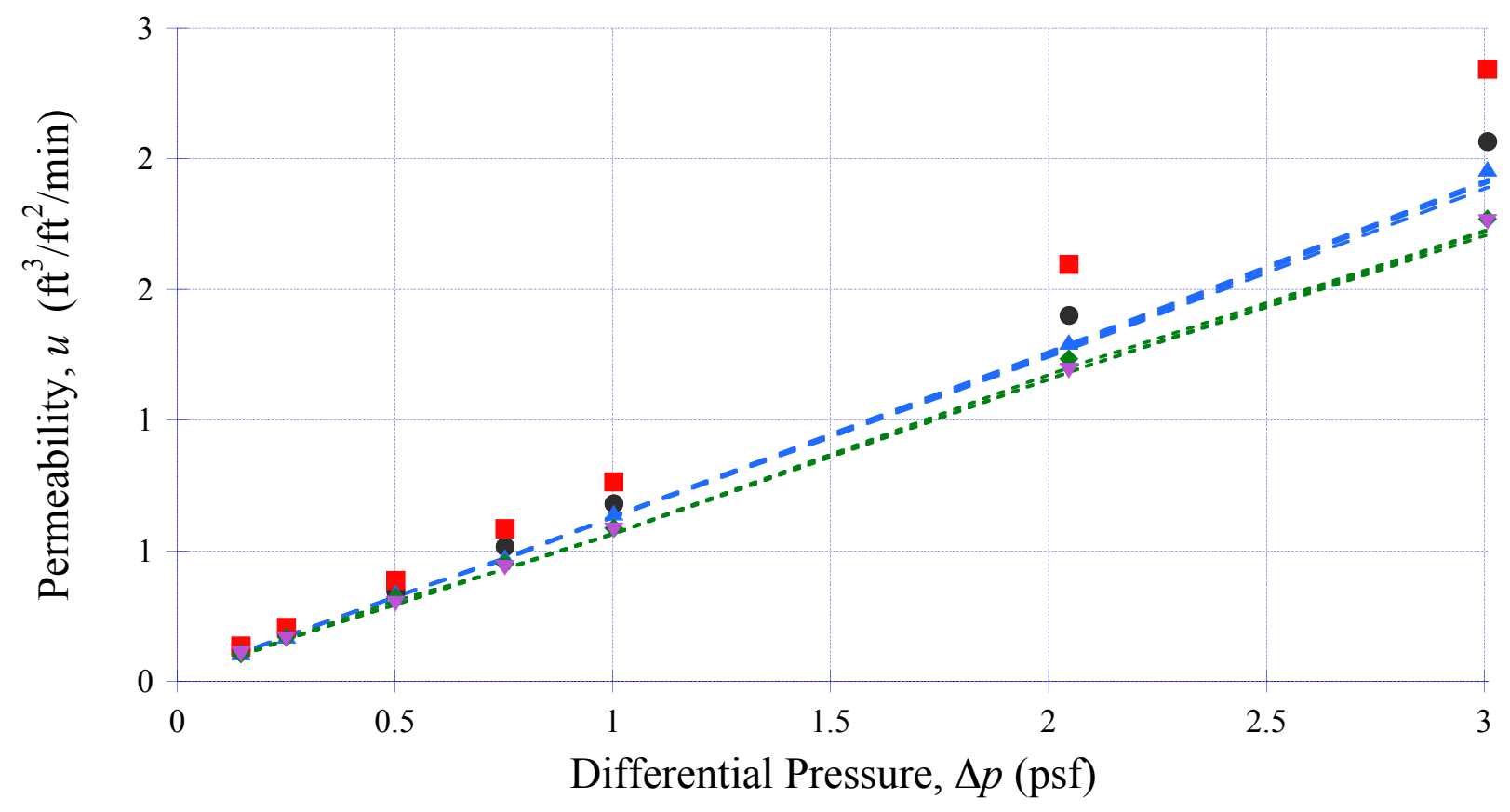

(b) Close up of the lower differential pressure range: 0.146-3 psf (7-143.6 Pa).

Figure B2. Original and replicate permeability results for PIA-C-44378D Type I fabric. 
Table B1. Replicate permeability results for PIA-C-7020D Type I fabric in chronological testing order.

\begin{tabular}{|c|c|c|c|c|c|c|c|c|c|c|c|c|c|}
\hline \multirow{2}{*}{$\begin{array}{l}\text { Sample/ } \\
\text { Replicate }\end{array}$} & \multirow{2}{*}{ Date } & \multirow{2}{*}{$\begin{array}{l}\text { Time } \\
(\mathrm{PST})\end{array}$} & \multicolumn{3}{|c|}{ Atmospheric Pressure, $p$} & \multicolumn{3}{|c|}{ Temperature, $T$} & \multirow{2}{*}{$\begin{array}{c}\text { Relative } \\
\text { Humidity, } \\
R H \\
(\%)\end{array}$} & \multicolumn{2}{|c|}{$\begin{array}{l}\text { Differential Pressure, } \\
\qquad \Delta p\end{array}$} & \multicolumn{2}{|c|}{ Permeability, $u$} \\
\hline & & & (in. $\mathrm{Hg}$ ) & (psf) & $(\mathrm{Pa})$ & $\left({ }^{\circ} \mathrm{F}\right)$ & $\left({ }^{\circ} \mathrm{R}\right)$ & $(\mathrm{K})$ & & (psf) & $(\mathrm{Pa})$ & $\left(\mathrm{ft}^{3} / \mathrm{ft}^{2} / \mathrm{min}\right)$ & $\left(\mathrm{cm}^{3} / \mathrm{cm}^{2} / \mathrm{s}\right)$ \\
\hline $3 / 1$ & $3 / 3 / 16$ & $5: 21$ & 27.68 & 1958 & 93735 & 69.5 & 529.2 & 294.0 & 17.7 & 0.146 & 7.0 & 9.27 & 4.71 \\
\hline $3 / 1$ & $3 / 3 / 16$ & $5: 25$ & 27.68 & 1958 & 93735 & 69.4 & 529.1 & 293.9 & 17.7 & 0.251 & 12.0 & 14.88 & 7.56 \\
\hline $3 / 1$ & $3 / 3 / 16$ & $5: 29$ & 27.68 & 1958 & 93735 & 69.2 & 528.9 & 293.8 & 17.7 & 2.047 & 98.0 & 82.48 & 41.90 \\
\hline $3 / 1$ & $3 / 3 / 16$ & $5: 33$ & 27.68 & 1958 & 93735 & 69.2 & 528.9 & 293.8 & 17.7 & 12.009 & 575.0 & 279.53 & 142.00 \\
\hline $3 / 1$ & $3 / 3 / 16$ & $5: 36$ & 27.68 & 1958 & 93735 & 69.2 & 528.9 & 293.8 & 17.7 & 5.994 & 287.0 & 178.15 & 90.50 \\
\hline $3 / 1$ & $3 / 3 / 16$ & $5: 40$ & 27.68 & 1958 & 93735 & 69.2 & 528.9 & 293.8 & 17.7 & 0.752 & 36.0 & 38.78 & 19.70 \\
\hline $3 / 1$ & $3 / 3 / 16$ & $5: 44$ & 27.68 & 1958 & 93735 & 69.2 & 528.9 & 293.8 & 17.3 & 25.000 & 1197.0 & 454.72 & 231.00 \\
\hline $3 / 1$ & $3 / 3 / 16$ & $5: 48$ & 27.68 & 1958 & 93735 & 69.3 & 529.0 & 293.9 & 17.4 & 1.003 & 48.0 & 49.02 & 24.90 \\
\hline $3 / 1$ & $3 / 3 / 16$ & $5: 52$ & 27.68 & 1958 & 93735 & 69.4 & 529.1 & 293.9 & 17.1 & 0.501 & 24.0 & 27.95 & 14.20 \\
\hline $3 / 1$ & $3 / 3 / 16$ & $5: 56$ & 27.69 & 1958 & 93769 & 69.3 & 529.0 & 293.9 & 17.1 & 3.008 & 144.0 & 110.63 & 56.20 \\
\hline $3 / 1$ & $3 / 3 / 16$ & $6: 00$ & 27.69 & 1958 & 93769 & 69.4 & 529.1 & 293.9 & 17.1 & 0.146 & 7.0 & 9.29 & 4.72 \\
\hline $3 / 2$ & $3 / 3 / 16$ & $6: 04$ & 27.69 & 1958 & 93769 & 70.0 & 529.7 & 294.3 & 16.6 & 0.146 & 7.0 & 9.27 & 4.71 \\
\hline $3 / 2$ & $3 / 3 / 16$ & $6: 08$ & 27.69 & 1958 & 93769 & 70.8 & 530.5 & 294.7 & 17.3 & 0.251 & 12.0 & 15.06 & 7.65 \\
\hline $3 / 2$ & $3 / 3 / 16$ & $6: 12$ & 27.69 & 1958 & 93769 & 72.3 & 532.0 & 295.5 & 15.5 & 2.047 & 98.0 & 83.07 & 42.20 \\
\hline $3 / 2$ & $3 / 3 / 16$ & $6: 16$ & 27.69 & 1958 & 93769 & 72.5 & 532.2 & 295.7 & 15.5 & 12.009 & 575.0 & 279.53 & 142.00 \\
\hline $3 / 2$ & $3 / 3 / 16$ & $6: 20$ & 27.69 & 1958 & 93769 & 72.2 & 531.9 & 295.5 & 15.6 & 5.994 & 287.0 & 178.74 & 90.80 \\
\hline $3 / 2$ & $3 / 3 / 16$ & $6: 24$ & 27.69 & 1958 & 93769 & 71.8 & 531.5 & 295.3 & 16.5 & 0.752 & 36.0 & 38.78 & 19.70 \\
\hline $3 / 2$ & $3 / 3 / 16$ & $6: 28$ & 27.69 & 1958 & 93769 & 71.7 & 531.4 & 295.2 & 16.6 & 25.000 & 1197.0 & 452.76 & 230.00 \\
\hline $3 / 2$ & $3 / 3 / 16$ & $6: 32$ & 27.69 & 1958 & 93769 & 71.4 & 531.1 & 295.0 & 16.6 & 1.003 & 48.0 & 49.02 & 24.90 \\
\hline $3 / 2$ & $3 / 3 / 16$ & $6: 36$ & 27.69 & 1958 & 93769 & 71.3 & 531.0 & 295.0 & 16.6 & 0.501 & 24.0 & 27.76 & 14.10 \\
\hline $3 / 2$ & $3 / 3 / 16$ & $6: 40$ & 27.69 & 1958 & 93769 & 71.2 & 530.9 & 294.9 & 16.6 & 3.008 & 144.0 & 111.02 & 56.40 \\
\hline $3 / 2$ & $3 / 3 / 16$ & $6: 44$ & 27.69 & 1958 & 93769 & 71.1 & 530.8 & 294.9 & 16.6 & 0.146 & 7.0 & 9.23 & 4.69 \\
\hline $3 / 3$ & $3 / 3 / 16$ & $6: 48$ & 27.69 & 1958 & 93769 & 71.2 & 530.9 & 294.9 & 16.6 & 0.146 & 7.0 & 9.21 & 4.68 \\
\hline $3 / 3$ & $3 / 3 / 16$ & $6: 52$ & 27.70 & 1959 & 93803 & 71.2 & 530.9 & 294.9 & 16.6 & 0.251 & 12.0 & 14.96 & 7.60 \\
\hline $3 / 3$ & $3 / 3 / 16$ & $6: 56$ & 27.70 & 1959 & 93803 & 71.1 & 530.8 & 294.9 & 16.6 & 2.047 & 98.0 & 83.86 & 42.60 \\
\hline $3 / 3$ & $3 / 3 / 16$ & $7: 00$ & 27.70 & 1959 & 93803 & 71.1 & 530.8 & 294.9 & 16.6 & 12.009 & 575.0 & 283.46 & 144.00 \\
\hline $3 / 3$ & $3 / 3 / 16$ & $7: 05$ & 27.70 & 1959 & 93803 & 71.0 & 530.7 & 294.8 & 16.6 & 5.994 & 287.0 & 179.92 & 91.40 \\
\hline $3 / 3$ & $3 / 3 / 16$ & 7:09 & 27.70 & 1959 & 93803 & 71.0 & 530.7 & 294.8 & 16.6 & 0.752 & 36.0 & 38.98 & 19.80 \\
\hline $3 / 3$ & $3 / 3 / 16$ & $7: 13$ & 27.70 & 1959 & 93803 & 71.0 & 530.7 & 294.8 & 16.6 & 25.000 & 1197.0 & 456.69 & 232.00 \\
\hline $3 / 3$ & $3 / 3 / 16$ & $7: 17$ & 27.71 & 1960 & 93837 & 71.0 & 530.7 & 294.8 & 16.6 & 1.003 & 48.0 & 49.21 & 25.00 \\
\hline $3 / 3$ & $3 / 3 / 16$ & $7: 21$ & 27.70 & 1959 & 93803 & 70.9 & 530.6 & 294.8 & 16.6 & 0.501 & 24.0 & 27.56 & 14.00 \\
\hline $3 / 3$ & $3 / 3 / 16$ & $7: 26$ & 27.71 & 1960 & 93837 & 70.9 & 530.6 & 294.8 & 16.6 & 3.008 & 144.0 & 110.43 & 56.10 \\
\hline $3 / 3$ & $3 / 3 / 16$ & $7: 30$ & 27.70 & 1959 & 93803 & 70.9 & 530.6 & 294.8 & 16.6 & 0.146 & 7.0 & 9.17 & 4.66 \\
\hline
\end{tabular}


Table B2. Replicate permeability results for PIA-C-44378D Type I fabric in chronological testing order.

\begin{tabular}{|c|c|c|c|c|c|c|c|c|c|c|c|c|c|}
\hline \multirow{2}{*}{$\begin{array}{l}\text { Sample/ } \\
\text { Replicate }\end{array}$} & \multirow{2}{*}{ Date } & \multirow{2}{*}{$\begin{array}{l}\text { Time } \\
\text { (PST) }\end{array}$} & \multicolumn{3}{|c|}{ Atmospheric Pressure, $p$} & \multicolumn{3}{|c|}{ Temperature, $T$} & \multirow{2}{*}{$\begin{array}{c}\text { Relative } \\
\text { Humidity, } \\
\text { RH } \\
(\%)\end{array}$} & \multicolumn{2}{|c|}{$\begin{array}{l}\text { Differential Pressure, } \\
\qquad \Delta p\end{array}$} & \multicolumn{2}{|c|}{ Permeability, $u$} \\
\hline & & & (in. $\mathrm{Hg}$ ) & (psf) & $(\mathrm{Pa})$ & $\left({ }^{\circ} \mathrm{F}\right)$ & $\left({ }^{\circ} \mathrm{R}\right)$ & $(\mathrm{K})$ & & (psf) & $(\mathrm{Pa})$ & $\left(\mathrm{ft}^{3} / \mathrm{ft}^{2} / \mathrm{min}\right)$ & $\left(\mathrm{cm}^{3} / \mathrm{cm}^{2} / \mathrm{s}\right)$ \\
\hline $3 / 1$ & $2 / 29 / 16$ & $6: 09$ & 27.73 & 1961 & 93905 & 72.7 & 532.4 & 295.8 & 26.1 & 0.146 & 7.0 & 0.1090 & 0.0554 \\
\hline $3 / 1$ & $2 / 29 / 16$ & $6: 14$ & 27.74 & 1962 & 93938 & 72.5 & 532.2 & 295.7 & 26.1 & 0.251 & 12.0 & 0.1730 & 0.0879 \\
\hline $3 / 1$ & $2 / 29 / 16$ & $6: 18$ & 27.74 & 1962 & 93938 & 72.3 & 532.0 & 295.5 & 26.1 & 2.047 & 98.0 & 1.2700 & 0.6452 \\
\hline $3 / 1$ & $2 / 29 / 16$ & $6: 22$ & 27.74 & 1962 & 93938 & 72.3 & 532.0 & 295.5 & 26.5 & 12.009 & 575.0 & 7.2100 & 3.6627 \\
\hline $3 / 1$ & $2 / 29 / 16$ & $6: 26$ & 27.74 & 1962 & 93938 & 72.2 & 531.9 & 295.5 & 26.7 & 5.994 & 287.0 & 3.7200 & 1.8898 \\
\hline $3 / 1$ & $2 / 29 / 16$ & $6: 30$ & 27.75 & 1963 & 93972 & 72.1 & 531.8 & 295.4 & 27.3 & 0.752 & 36.0 & 0.4660 & 0.2367 \\
\hline $3 / 1$ & $2 / 29 / 16$ & $6: 34$ & 27.74 & 1962 & 93938 & 72.0 & 531.7 & 295.4 & 27.3 & 25.000 & 1197.0 & 14.5000 & 7.3660 \\
\hline $3 / 1$ & $2 / 29 / 16$ & $6: 38$ & 27.75 & 1963 & 93972 & 71.9 & 531.6 & 295.3 & 27.3 & 1.003 & 48.0 & 0.6280 & 0.3190 \\
\hline $3 / 1$ & $2 / 29 / 16$ & $6: 42$ & 27.75 & 1963 & 93972 & 71.8 & 531.5 & 295.3 & 27.3 & 0.501 & 24.0 & 0.3240 & 0.1646 \\
\hline $3 / 1$ & $2 / 29 / 16$ & $6: 46$ & 27.74 & 1962 & 93938 & 71.8 & 531.5 & 295.3 & 27.3 & 3.008 & 144.0 & 1.8900 & 0.9601 \\
\hline $3 / 1$ & $2 / 29 / 16$ & $6: 50$ & 27.74 & 1962 & 93938 & 71.8 & 531.5 & 295.3 & 27.3 & 0.146 & 7.0 & 0.1090 & 0.0554 \\
\hline $3 / 2$ & $2 / 29 / 16$ & $6: 56$ & 27.74 & 1962 & 93938 & 71.7 & 531.4 & 295.2 & 27.3 & 0.146 & 7.0 & 0.1100 & 0.0559 \\
\hline $3 / 2$ & $2 / 29 / 16$ & $6: 59$ & 27.75 & 1963 & 93972 & 71.7 & 531.4 & 295.2 & 27.3 & 0.251 & 12.0 & 0.1750 & 0.0889 \\
\hline $3 / 2$ & $2 / 29 / 16$ & $7: 04$ & 27.74 & 1962 & 93938 & 71.8 & 531.5 & 295.3 & 27.3 & 2.047 & 98.0 & 1.2800 & 0.6502 \\
\hline $3 / 2$ & $2 / 29 / 16$ & $7: 08$ & 27.75 & 1963 & 93972 & 71.8 & 531.5 & 295.3 & 27.3 & 12.009 & 575.0 & 7.2900 & 3.7033 \\
\hline $3 / 2$ & $2 / 29 / 16$ & $7: 12$ & 27.76 & 1963 & 94006 & 71.8 & 531.5 & 295.3 & 27.3 & 5.994 & 287.0 & 3.7500 & 1.9050 \\
\hline $3 / 2$ & $2 / 29 / 16$ & $7: 16$ & 27.75 & 1963 & 93972 & 71.8 & 531.5 & 295.3 & 27.3 & 0.752 & 36.0 & 0.4730 & 0.2403 \\
\hline $3 / 2$ & $2 / 29 / 16$ & $7: 20$ & 27.76 & 1963 & 94006 & 71.7 & 531.4 & 295.2 & 27.7 & 25.000 & 1197.0 & 14.6000 & 7.4168 \\
\hline $3 / 2$ & $2 / 29 / 16$ & $7: 24$ & 27.76 & 1963 & 94006 & 71.7 & 531.4 & 295.2 & 27.8 & 1.003 & 48.0 & 0.6320 & 0.3211 \\
\hline $3 / 2$ & $2 / 29 / 16$ & $7: 28$ & 27.76 & 1963 & 94006 & 71.7 & 531.4 & 295.2 & 27.8 & 0.501 & 24.0 & 0.3250 & 0.1651 \\
\hline $3 / 2$ & $2 / 29 / 16$ & $7: 32$ & 27.77 & 1964 & 94040 & 71.6 & 531.3 & 295.2 & 27.8 & 3.008 & 144.0 & 1.9100 & 0.9703 \\
\hline $3 / 2$ & $2 / 29 / 16$ & $7: 37$ & 27.76 & 1963 & 94006 & 71.6 & 531.3 & 295.2 & 27.8 & 0.146 & 7.0 & 0.1100 & 0.0559 \\
\hline $3 / 3$ & $2 / 29 / 16$ & $7: 41$ & 27.77 & 1964 & 94040 & 71.6 & 531.3 & 295.2 & 28.3 & 0.146 & 7.0 & 0.1100 & 0.0559 \\
\hline $3 / 3$ & $2 / 29 / 16$ & $7: 45$ & 27.77 & 1964 & 94040 & 71.6 & 531.3 & 295.2 & 28.4 & 0.251 & 12.0 & 0.1700 & 0.0864 \\
\hline $3 / 3$ & $2 / 29 / 16$ & $7: 49$ & 27.77 & 1964 & 94040 & 71.6 & 531.3 & 295.2 & 28.4 & 2.047 & 98.0 & 1.2900 & 0.6553 \\
\hline $3 / 3$ & $2 / 29 / 16$ & $7: 53$ & 27.77 & 1964 & 94040 & 71.6 & 531.3 & 295.2 & 28.4 & 12.009 & 575.0 & 7.3500 & 3.7338 \\
\hline $3 / 3$ & $2 / 29 / 16$ & $7: 57$ & 27.77 & 1964 & 94040 & 71.7 & 531.4 & 295.2 & 28.4 & 5.994 & 287.0 & 3.7600 & 1.9101 \\
\hline $3 / 3$ & $2 / 29 / 16$ & $8: 01$ & 27.77 & 1964 & 94040 & 71.7 & 531.4 & 295.2 & 28.4 & 0.752 & 36.0 & 0.4690 & 0.2383 \\
\hline $3 / 3$ & $2 / 29 / 16$ & $8: 05$ & 27.77 & 1964 & 94040 & 71.8 & 531.5 & 295.3 & 28.3 & 25.000 & 1197.0 & 14.7000 & 7.4676 \\
\hline $3 / 3$ & $2 / 29 / 16$ & $8: 10$ & 27.77 & 1964 & 94040 & 71.9 & 531.6 & 295.3 & 28.4 & 1.003 & 48.0 & 0.6330 & 0.3216 \\
\hline $3 / 3$ & $2 / 29 / 16$ & $8: 15$ & 27.77 & 1964 & 94040 & 72.0 & 531.7 & 295.4 & 28.2 & 0.501 & 24.0 & 0.3240 & 0.1646 \\
\hline $3 / 3$ & $2 / 29 / 16$ & $8: 20$ & 27.77 & 1964 & 94040 & 72.1 & 531.8 & 295.4 & 28.4 & 3.008 & 144.0 & 1.9200 & 0.9754 \\
\hline $3 / 3$ & $2 / 29 / 16$ & $8: 24$ & 27.78 & 1965 & 94074 & 72.1 & 531.8 & 295.4 & 28.3 & 0.146 & 7.0 & 0.1090 & 0.0554 \\
\hline
\end{tabular}


Table B2. Replicate permeability results for PIA-C-44378D Type I fabric in chronological testing order. Concluded.

\begin{tabular}{|c|c|c|c|c|c|c|c|c|c|c|c|c|c|}
\hline \multirow{2}{*}{$\begin{array}{l}\text { Sample/ } \\
\text { Replicate }\end{array}$} & \multirow[t]{2}{*}{ Date } & \multirow{2}{*}{$\begin{array}{l}\text { Time } \\
\text { (PST) }\end{array}$} & \multicolumn{3}{|c|}{ Atmospheric Pressure, $p$} & \multicolumn{3}{|c|}{ Temperature, $T$} & \multirow{2}{*}{$\begin{array}{c}\text { Relative } \\
\text { Humidity, } \\
R H \\
(\%)\end{array}$} & \multicolumn{2}{|c|}{$\begin{array}{l}\text { Differential Pressure, } \\
\qquad \Delta p\end{array}$} & \multicolumn{2}{|c|}{ Permeability, $u$} \\
\hline & & & (in. $\mathrm{Hg}$ ) & (psf) & $(\mathrm{Pa})$ & $\left({ }^{\circ} \mathrm{F}\right)$ & $\left({ }^{\circ} \mathrm{R}\right)$ & $(\mathrm{K})$ & & (psf) & $(\mathrm{Pa})$ & $\left(\mathrm{ft}^{3} / \mathrm{ft}^{2} / \min \right)$ & $\left(\mathrm{cm}^{3} / \mathrm{cm}^{2} / \mathrm{s}\right)$ \\
\hline $4 / 1$ & $3 / 3 / 16$ & $7: 43$ & 27.71 & 1960 & 93837 & 71.0 & 530.7 & 294.8 & 16.6 & 0.146 & 7.0 & 0.0996 & 0.0506 \\
\hline $4 / 1$ & $3 / 3 / 16$ & $7: 48$ & 27.71 & 1960 & 93837 & 71.0 & 530.7 & 294.8 & 16.6 & 3.008 & 144.0 & 1.7087 & 0.8680 \\
\hline $4 / 1$ & $3 / 3 / 16$ & $7: 52$ & 27.71 & 1960 & 93837 & 71.1 & 530.8 & 294.9 & 16.6 & 1.003 & 48.0 & 0.5630 & 0.2860 \\
\hline $4 / 1$ & $3 / 3 / 16$ & $7: 56$ & 27.71 & 1960 & 93837 & 71.1 & 530.8 & 294.9 & 16.6 & 25.000 & 1197.0 & 13.4055 & 6.8100 \\
\hline $4 / 1$ & $3 / 3 / 16$ & $8: 00$ & 27.71 & 1960 & 93837 & 71.1 & 530.8 & 294.9 & 16.6 & 2.047 & 98.0 & 1.1831 & 0.6010 \\
\hline $4 / 1$ & $3 / 3 / 16$ & $8: 04$ & 27.71 & 1960 & 93837 & 71.1 & 530.8 & 294.9 & 16.6 & 0.251 & 12.0 & 0.1614 & 0.0820 \\
\hline $4 / 1$ & $3 / 3 / 16$ & $8: 08$ & 27.71 & 1960 & 93837 & 71.2 & 530.9 & 294.9 & 16.6 & 5.994 & 287.0 & 3.4252 & 1.7400 \\
\hline $4 / 1$ & $3 / 3 / 16$ & $8: 12$ & 27.72 & 1961 & 93871 & 71.3 & 531.0 & 295.0 & 16.6 & 0.752 & 36.0 & 0.4291 & 0.2180 \\
\hline $4 / 1$ & $3 / 3 / 16$ & $8: 16$ & 27.72 & 1961 & 93871 & 71.4 & 531.1 & 295.0 & 16.6 & 0.501 & 24.0 & 0.3091 & 0.1570 \\
\hline $4 / 1$ & $3 / 3 / 16$ & $8: 21$ & 27.72 & 1961 & 93871 & 71.5 & 531.2 & 295.1 & 16.6 & 12.009 & 575.0 & 6.7323 & 3.4200 \\
\hline $4 / 1$ & $3 / 3 / 16$ & $8: 25$ & 27.72 & 1961 & 93871 & 71.6 & 531.3 & 295.2 & 16.6 & 0.146 & 7.0 & 0.1006 & 0.0511 \\
\hline $4 / 2$ & $3 / 3 / 16$ & $8: 30$ & 27.72 & 1961 & 93871 & 71.7 & 531.4 & 295.2 & 16.6 & 0.146 & 7.0 & 0.1004 & 0.0510 \\
\hline $4 / 2$ & $3 / 3 / 16$ & $8: 35$ & 27.72 & 1961 & 93871 & 71.8 & 531.5 & 295.3 & 16.6 & 3.008 & 144.0 & 1.7224 & 0.8750 \\
\hline $4 / 2$ & $3 / 3 / 16$ & $8: 39$ & 27.72 & 1961 & 93871 & 71.9 & 531.6 & 295.3 & 16.6 & 1.003 & 48.0 & 0.5669 & 0.2880 \\
\hline $4 / 2$ & $3 / 3 / 16$ & $8: 43$ & 27.72 & 1961 & 93871 & 72.1 & 531.8 & 295.4 & 16.6 & 25.000 & 1197.0 & 13.6024 & 6.9100 \\
\hline $4 / 2$ & $3 / 3 / 16$ & $8: 47$ & 27.72 & 1961 & 93871 & 72.1 & 531.8 & 295.4 & 16.6 & 2.047 & 98.0 & 1.1831 & 0.6010 \\
\hline $4 / 2$ & $3 / 3 / 16$ & $8: 52$ & 27.72 & 1961 & 93871 & 72.1 & 531.8 & 295.4 & 16.6 & 0.251 & 12.0 & 0.1596 & 0.0811 \\
\hline $4 / 2$ & $3 / 3 / 16$ & $8: 56$ & 27.72 & 1961 & 93871 & 72.3 & 532.0 & 295.5 & 16.6 & 5.994 & 287.0 & 3.4252 & 1.7400 \\
\hline $4 / 2$ & $3 / 3 / 16$ & $9: 01$ & 27.72 & 1961 & 93871 & 72.3 & 532.0 & 295.5 & 16.6 & 0.752 & 36.0 & 0.4311 & 0.2190 \\
\hline $4 / 2$ & $3 / 3 / 16$ & $9: 05$ & 27.72 & 1961 & 93871 & 72.4 & 532.1 & 295.6 & 16.6 & 0.501 & 24.0 & 0.2933 & 0.1490 \\
\hline $4 / 2$ & $3 / 3 / 16$ & $9: 09$ & 27.72 & 1961 & 93871 & 72.5 & 532.2 & 295.7 & 16.6 & 12.009 & 575.0 & 6.7520 & 3.4300 \\
\hline $4 / 2$ & $3 / 3 / 16$ & $9: 13$ & 27.72 & 1961 & 93871 & 72.6 & 532.3 & 295.7 & 16.6 & 0.146 & 7.0 & 0.0992 & 0.0504 \\
\hline $4 / 3$ & $3 / 3 / 16$ & $9: 22$ & 27.72 & 1961 & 93871 & 72.9 & 532.6 & 295.9 & 15.5 & 0.146 & 7.0 & 0.1000 & 0.0508 \\
\hline $4 / 3$ & $3 / 3 / 16$ & $9: 26$ & 27.72 & 1961 & 93871 & 73.0 & 532.7 & 295.9 & 15.5 & 3.008 & 144.0 & 1.7283 & 0.8780 \\
\hline $4 / 3$ & $3 / 3 / 16$ & $9: 30$ & 27.72 & 1961 & 93871 & 73.2 & 532.9 & 296.0 & 15.5 & 1.003 & 48.0 & 0.5650 & 0.2870 \\
\hline $4 / 3$ & $3 / 3 / 16$ & $9: 34$ & 27.71 & 1960 & 93837 & 71.1 & 530.8 & 294.9 & 16.6 & 25.000 & 1197.0 & 13.7008 & 6.9600 \\
\hline $4 / 3$ & $3 / 3 / 16$ & $9: 38$ & 27.72 & 1961 & 93871 & 69.0 & 528.7 & 293.7 & 17.7 & 2.047 & 98.0 & 1.2008 & 0.6100 \\
\hline $4 / 3$ & $3 / 3 / 16$ & $9: 42$ & 27.72 & 1961 & 93871 & 68.0 & 527.7 & 293.2 & 18.7 & 0.251 & 12.0 & 0.1610 & 0.0818 \\
\hline $4 / 3$ & $3 / 3 / 16$ & $9: 46$ & 27.72 & 1961 & 93871 & 69.4 & 529.1 & 293.9 & 17.7 & 5.994 & 287.0 & 3.4646 & 1.7600 \\
\hline $4 / 3$ & $3 / 3 / 16$ & $9: 51$ & 27.72 & 1961 & 93871 & 70.5 & 530.2 & 294.5 & 16.6 & 0.752 & 36.0 & 0.4311 & 0.2190 \\
\hline $4 / 3$ & $3 / 3 / 16$ & $9: 55$ & 27.72 & 1961 & 93871 & 71.2 & 530.9 & 294.9 & 16.6 & 0.501 & 24.0 & 0.2953 & 0.1500 \\
\hline $4 / 3$ & $3 / 3 / 16$ & $10: 00$ & 27.72 & 1961 & 93871 & 72.1 & 531.8 & 295.4 & 15.5 & 12.009 & 575.0 & 6.7913 & 3.4500 \\
\hline $4 / 3$ & $3 / 3 / 16$ & $10: 04$ & 27.72 & 1961 & 93871 & 72.2 & 531.9 & 295.5 & 15.5 & 0.146 & 7.0 & 0.1022 & 0.0519 \\
\hline
\end{tabular}




\section{Appendix C Effective Porosity Test Results}

Table C1. Effective porosity results for PIA-C-7020D Type I fabric.

\begin{tabular}{|c|c|c|c|c|c|}
\hline \multicolumn{2}{|c|}{$\hat{R} e$} & \multirow{2}{*}{$c_{e}$} & \multicolumn{2}{|c|}{$\hat{R} e$} & \multirow{2}{*}{$c_{e}$} \\
\hline$(1 / \mathrm{ft})$ & $(1 / \mathrm{m})$ & & $(1 / \mathrm{ft})$ & $(1 / \mathrm{m})$ & \\
\hline $6.556 \mathrm{E}+04$ & $2.151 \mathrm{E}+05$ & 0.01157 & $1.724 \mathrm{E}+05$ & $5.656 \mathrm{E}+05$ & 0.02370 \\
\hline $6.556 \mathrm{E}+04$ & $2.151 \mathrm{E}+05$ & 0.01345 & $1.728 \mathrm{E}+05$ & $5.670 \mathrm{E}+05$ & 0.02599 \\
\hline $6.557 \mathrm{E}+04$ & $2.151 \mathrm{E}+05$ & 0.01314 & $2.455 \mathrm{E}+05$ & $8.054 \mathrm{E}+05$ & 0.03400 \\
\hline $6.566 \mathrm{E}+04$ & $2.154 \mathrm{E}+05$ & 0.01214 & $2.455 \mathrm{E}+05$ & $8.055 \mathrm{E}+05$ & 0.03025 \\
\hline $6.566 \mathrm{E}+04$ & $2.154 \mathrm{E}+05$ & 0.01146 & $2.459 \mathrm{E}+05$ & $8.067 \mathrm{E}+05$ & 0.03118 \\
\hline $6.570 \mathrm{E}+04$ & $2.155 \mathrm{E}+05$ & 0.01161 & $2.459 \mathrm{E}+05$ & $8.069 \mathrm{E}+05$ & 0.02937 \\
\hline $6.570 \mathrm{E}+04$ & $2.155 \mathrm{E}+05$ & 0.01217 & $2.469 \mathrm{E}+05$ & $8.100 \mathrm{E}+05$ & 0.03124 \\
\hline $6.583 \mathrm{E}+04$ & $2.160 \mathrm{E}+05$ & 0.01139 & $2.974 \mathrm{E}+05$ & $9.758 \mathrm{E}+05$ & 0.03704 \\
\hline $6.585 \mathrm{E}+04$ & $2.160 \mathrm{E}+05$ & 0.01281 & $2.977 \mathrm{E}+05$ & $9.766 \mathrm{E}+05$ & 0.03253 \\
\hline $6.615 \mathrm{E}+04$ & $2.170 \mathrm{E}+05$ & 0.01300 & $2.978 \mathrm{E}+05$ & $9.771 \mathrm{E}+05$ & 0.03453 \\
\hline $8.584 \mathrm{E}+04$ & $2.816 \mathrm{E}+05$ & 0.01698 & $2.985 \mathrm{E}+05$ & $9.794 \mathrm{E}+05$ & 0.03121 \\
\hline $8.589 \mathrm{E}+04$ & $2.818 \mathrm{E}+05$ & 0.01477 & $2.991 \mathrm{E}+05$ & $9.814 \mathrm{E}+05$ & 0.03411 \\
\hline $8.605 \mathrm{E}+04$ & $2.823 \mathrm{E}+05$ & 0.01541 & $4.198 \mathrm{E}+05$ & $1.377 \mathrm{E}+06$ & 0.04245 \\
\hline $8.613 \mathrm{E}+04$ & $2.826 \mathrm{E}+05$ & 0.01436 & $4.201 \mathrm{E}+05$ & $1.378 \mathrm{E}+06$ & 0.03768 \\
\hline $8.655 \mathrm{E}+04$ & $2.840 \mathrm{E}+05$ & 0.01619 & $4.207 \mathrm{E}+05$ & $1.380 \mathrm{E}+06$ & 0.03920 \\
\hline $1.214 \mathrm{E}+05$ & $3.982 \mathrm{E}+05$ & 0.02249 & $4.212 \mathrm{E}+05$ & $1.382 \mathrm{E}+06$ & 0.03597 \\
\hline $1.214 \mathrm{E}+05$ & $3.982 \mathrm{E}+05$ & 0.01991 & $4.222 \mathrm{E}+05$ & $1.385 \mathrm{E}+06$ & 0.03906 \\
\hline $1.216 \mathrm{E}+05$ & $3.989 \mathrm{E}+05$ & 0.02099 & $5.940 \mathrm{E}+05$ & $1.949 \mathrm{E}+06$ & 0.04222 \\
\hline $1.218 \mathrm{E}+05$ & $3.996 \mathrm{E}+05$ & 0.01903 & $5.942 \mathrm{E}+05$ & $1.949 \mathrm{E}+06$ & 0.04751 \\
\hline $1.223 \mathrm{E}+05$ & $4.014 \mathrm{E}+05$ & 0.02106 & $5.955 \mathrm{E}+05$ & $1.954 \mathrm{E}+06$ & 0.04383 \\
\hline $1.486 \mathrm{E}+05$ & $4.874 \mathrm{E}+05$ & 0.02580 & $5.957 \mathrm{E}+05$ & $1.954 \mathrm{E}+06$ & 0.04105 \\
\hline $1.487 \mathrm{E}+05$ & $4.879 \mathrm{E}+05$ & 0.02296 & $5.974 \mathrm{E}+05$ & $1.960 \mathrm{E}+06$ & 0.04360 \\
\hline $1.490 \mathrm{E}+05$ & $4.888 \mathrm{E}+05$ & 0.02398 & $8.567 \mathrm{E}+05$ & $2.811 \mathrm{E}+06$ & 0.05314 \\
\hline $1.491 \mathrm{E}+05$ & $4.890 \mathrm{E}+05$ & 0.02237 & $8.580 \mathrm{E}+05$ & $2.815 \mathrm{E}+06$ & 0.04672 \\
\hline $1.498 \mathrm{E}+05$ & $4.914 \mathrm{E}+05$ & 0.02392 & $8.588 \mathrm{E}+05$ & $2.818 \mathrm{E}+06$ & 0.04954 \\
\hline $1.718 \mathrm{E}+05$ & $5.637 \mathrm{E}+05$ & 0.02473 & $8.597 \mathrm{E}+05$ & $2.821 \mathrm{E}+06$ & 0.04505 \\
\hline $1.720 \mathrm{E}+05$ & $5.642 \mathrm{E}+05$ & 0.02635 & $8.614 \mathrm{E}+05$ & $2.826 \mathrm{E}+06$ & 0.04876 \\
\hline $1.722 \mathrm{E}+05$ & $5.651 \mathrm{E}+05$ & 0.02830 & & & \\
\hline
\end{tabular}


Table C2. Effective porosity results for PIA-C-44378D Type I fabric.

\begin{tabular}{|c|c|c|c|c|c|}
\hline \multicolumn{2}{|c|}{$\hat{R} e$} & \multirow{2}{*}{$c_{e}$} & \multicolumn{2}{|c|}{$\hat{R} e$} & \multirow{2}{*}{$c_{e}$} \\
\hline$(1 / \mathrm{ft})$ & $(1 / \mathrm{m})$ & & $(1 / \mathrm{ft})$ & $(1 / \mathrm{m})$ & \\
\hline $6.571 \mathrm{E}+04$ & $2.156 \mathrm{E}+05$ & 0.0001611 & $1.733 \mathrm{E}+05$ & $5.687 \mathrm{E}+05$ & 0.0003211 \\
\hline $6.576 \mathrm{E}+04$ & $2.158 \mathrm{E}+05$ & 0.0001868 & $1.744 \mathrm{E}+05$ & $5.722 \mathrm{E}+05$ & 0.0003176 \\
\hline $6.576 \mathrm{E}+04$ & $2.158 \mathrm{E}+05$ & 0.0001581 & $2.460 \mathrm{E}+05$ & $8.070 \mathrm{E}+05$ & 0.0004962 \\
\hline $6.581 \mathrm{E}+04$ & $2.159 \mathrm{E}+05$ & 0.0001931 & $2.461 \mathrm{E}+05$ & $8.073 \mathrm{E}+05$ & 0.0006098 \\
\hline $6.590 \mathrm{E}+04$ & $2.162 \mathrm{E}+05$ & 0.0001733 & $2.474 \mathrm{E}+05$ & $8.115 \mathrm{E}+05$ & 0.0005370 \\
\hline $6.608 \mathrm{E}+04$ & $2.168 \mathrm{E}+05$ & 0.0001545 & $2.478 \mathrm{E}+05$ & $8.131 \mathrm{E}+05$ & 0.0004730 \\
\hline $6.614 \mathrm{E}+04$ & $2.170 \mathrm{E}+05$ & 0.0001526 & $2.493 \mathrm{E}+05$ & $8.180 \mathrm{E}+05$ & 0.0004568 \\
\hline $6.636 \mathrm{E}+04$ & $2.177 \mathrm{E}+05$ & 0.0001718 & $2.980 \mathrm{E}+05$ & $9.777 \mathrm{E}+05$ & 0.0006182 \\
\hline $6.643 \mathrm{E}+04$ & $2.179 \mathrm{E}+05$ & 0.0001526 & $2.983 \mathrm{E}+05$ & $9.788 \mathrm{E}+05$ & 0.0007383 \\
\hline $6.643 \mathrm{E}+04$ & $2.179 \mathrm{E}+05$ & 0.0001484 & $2.997 \mathrm{E}+05$ & $9.834 \mathrm{E}+05$ & 0.0005589 \\
\hline $8.607 \mathrm{E}+04$ & $2.824 \mathrm{E}+05$ & 0.0001912 & $3.003 \mathrm{E}+05$ & $9.851 \mathrm{E}+05$ & 0.0006537 \\
\hline $8.612 \mathrm{E}+04$ & $2.826 \mathrm{E}+05$ & 0.0002257 & $3.023 \mathrm{E}+05$ & $9.918 \mathrm{E}+05$ & 0.0005572 \\
\hline $8.625 \mathrm{E}+04$ & $2.830 \mathrm{E}+05$ & 0.0002071 & $4.209 \mathrm{E}+05$ & $1.381 \mathrm{E}+06$ & 0.0008478 \\
\hline $8.681 \mathrm{E}+04$ & $2.848 \mathrm{E}+05$ & 0.0001844 & $4.212 \mathrm{E}+05$ & $1.382 \mathrm{E}+06$ & 0.0010196 \\
\hline $8.700 \mathrm{E}+04$ & $2.854 \mathrm{E}+05$ & 0.0001774 & $4.241 \mathrm{E}+05$ & $1.391 \mathrm{E}+06$ & 0.0008910 \\
\hline $1.217 \mathrm{E}+05$ & $3.992 \mathrm{E}+05$ & 0.0002627 & $4.245 \mathrm{E}+05$ & $1.393 \mathrm{E}+06$ & 0.0008026 \\
\hline $1.218 \mathrm{E}+05$ & $3.997 \mathrm{E}+05$ & 0.0002979 & $4.270 \mathrm{E}+05$ & $1.401 \mathrm{E}+06$ & 0.0007869 \\
\hline $1.220 \mathrm{E}+05$ & $4.002 \mathrm{E}+05$ & 0.0002663 & $5.957 \mathrm{E}+05$ & $1.954 \mathrm{E}+06$ & 0.0011637 \\
\hline $1.229 \mathrm{E}+05$ & $4.031 \mathrm{E}+05$ & 0.0002487 & $5.960 \mathrm{E}+05$ & $1.956 \mathrm{E}+06$ & 0.0014435 \\
\hline $1.231 \mathrm{E}+05$ & $4.039 \mathrm{E}+05$ & 0.0002306 & $6.007 \mathrm{E}+05$ & $1.971 \mathrm{E}+06$ & 0.0012593 \\
\hline $1.490 \mathrm{E}+05$ & $4.890 \mathrm{E}+05$ & 0.0003001 & $6.016 \mathrm{E}+05$ & $1.974 \mathrm{E}+06$ & 0.0011284 \\
\hline $1.491 \mathrm{E}+05$ & $4.893 \mathrm{E}+05$ & 0.0003685 & $6.031 \mathrm{E}+05$ & $1.979 \mathrm{E}+06$ & 0.0011077 \\
\hline $1.496 \mathrm{E}+05$ & $4.907 \mathrm{E}+05$ & 0.0003257 & $8.593 \mathrm{E}+05$ & $2.819 \mathrm{E}+06$ & 0.0016214 \\
\hline $1.504 \mathrm{E}+05$ & $4.934 \mathrm{E}+05$ & 0.0002852 & $8.600 \mathrm{E}+05$ & $2.821 \mathrm{E}+06$ & 0.0019795 \\
\hline $1.509 \mathrm{E}+05$ & $4.952 \mathrm{E}+05$ & 0.0002756 & $8.660 \mathrm{E}+05$ & $2.841 \mathrm{E}+06$ & 0.0015584 \\
\hline $1.721 \mathrm{E}+05$ & $5.645 \mathrm{E}+05$ & 0.0003522 & $8.666 \mathrm{E}+05$ & $2.843 \mathrm{E}+06$ & 0.0015847 \\
\hline $1.723 \mathrm{E}+05$ & $5.652 \mathrm{E}+05$ & 0.0004170 & $8.674 \mathrm{E}+05$ & $2.846 \mathrm{E}+06$ & 0.0017806 \\
\hline $1.729 \mathrm{E}+05$ & $5.674 \mathrm{E}+05$ & 0.0003727 & & & \\
\hline
\end{tabular}




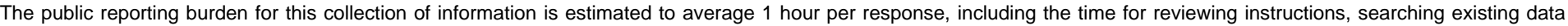

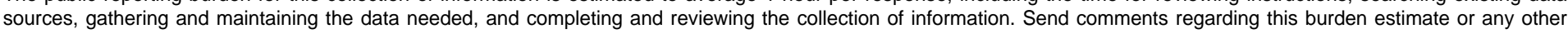

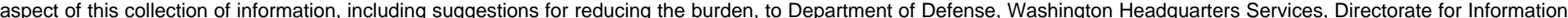

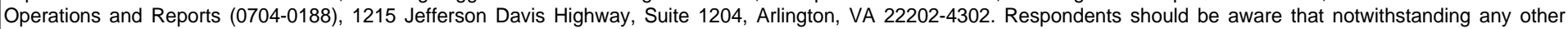

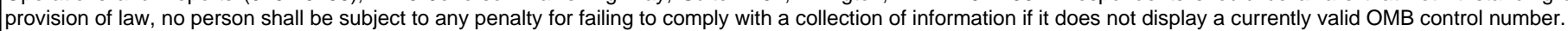
PLEASE DO NOT RETURN YOUR FORM TO THE ABOVE ADDRESS.
1. REPORT DATE (DD-MM-YYYY)
2. REPORT TYPE
3. DATES COVERED (From - To)
01- $07-2016$
Technical Memorandum

4. TITLE AND SUBTITLE

Permeability of Two Parachute Fabrics - Measurements, Modeling, and Application

5b. GRANT NUMBER

5c. PROGRAM ELEMENT NUMBER

6. AUTHOR(S)

5d. PROJECT NUMBER

5e. TASK NUMBER

Cruz, Juan R.; O'Farrell, Clara; Hennings, Elsa J.; Runnells, Paul

5f. WORK UNIT NUMBER

869021.05.07.11.99

7. PERFORMING ORGANIZATION NAME(S) AND ADDRESS(ES)

8. PERFORMING ORGANIZATION REPORT NUMBER

NASA Langley Research Center

Hampton, VA 23681-2199

L-20767

9. SPONSORING/MONITORING AGENCY NAME(S) AND ADDRESS(ES)

10. SPONSOR/MONITOR'S ACRONYM(S)

National Aeronautics and Space Administration

NASA

Washington, DC 20546-0001

11. SPONSOR/MONITOR'S REPORT NUMBER(S)

NASA-TM-2016-219328(Corrected Copy)

\section{DISTRIBUTIONIAVAILABILITY STATEMENT}

Unclassified - Unlimited

Subject Category 01

Availability: NASA STI Program (757) 864-9658

13. SUPPLEMENTARY NOTES Corrected errors in the calculation of the effective porosity (and its consequences) in the example of section 4.3, "Effective Porosity." Corrections did not change conclusions drawn from the example.

\section{ABSTRACT}

Two parachute fabrics, described by Parachute Industry Specifications PIA-C-7020D Type I and PIA-C-44378D Type I, were tested to obtain their permeabilities in air (i.e., flow through volume of air per area per time) over the range of differential pressures from $0.146 \mathrm{psf}$ ( $7 \mathrm{~Pa}$ ) to $25 \mathrm{psf}$ (1197 Pa). Both fabrics met their specific ation permeabilities at the standard differential pressure of 0.5 inch of water $(2.60 \mathrm{psf}, 124 \mathrm{~Pa})$. The permeability re sults were transformed into an effective porosity for use in calculations related to parachutes. Models were created that related the effective porosity to the unit Reynolds number for each of the fabrics. As an application example, these models were used to calc ulate the total porosities for two geometrically equiva lent subscale Disk Gap Band (DGB) parachutes fabricated from each of the two fabrics, and tested at the same operating conditions in a wind tunnel. Using the calculated total porosities and the results of the wind tunnel tests, the drag coefficient of a geometrically equivalent full-scale DGB operating on Mars was estimated.

\section{SUBJECT TERMS}

Fabric Permeability; Parachute Fabric; Parachutes

16. SECURITY CLASSIFICATION OF:

a. REPORT

\section{b. ABSTRACT}

U

U c. THIS PAGE

U
17. LIMITATION OF ABSTRACT

UU
18. NUMBER OF PAGES 38 19a. NAME OF RESPONSIBLE PERSON

STI Help Desk (email: help@sti.nasa.gov)

19b. TELEPHONE NUMBER (Include area code) (757) 864-9658 